\title{
Experimental identification of shaft misalignment in a turbo-generator system
}

\author{
MOHIT LAL ${ }^{1, *}$ and RAJIV TIWARI ${ }^{2}$ \\ ${ }^{1}$ Department of Industrial Design, National Institute of Technology Rourkela, Rourkela 769 008, India \\ ${ }^{2}$ Department of Mechanical Engineering, Indian Institute of Technology Guwahati, Guwahati 781 039, India \\ e-mail: lalm@nitrkl.ac.in; rtiwari@iitg.ernet.in
}

MS received 30 March 2016; revised 4 December 2016; accepted 7 September 2017; published online 15 May 2018

\begin{abstract}
Precise and authentic estimation of the dynamic features of rotating machines and prevention of failure requires accurate experimental characterisation of their critical components, for example, bearings and couplings. These are difficult to model theoretically, and they often suffer from uncertain parameters in their model. Especially, when there is a misalignment in the rotor system, dynamic characterisation of bearings and couplings changes drastically. In the present study, multiple fault parameters (MFPs) of critical components of turbo-generator, that is, bearing and coupling together with residual unbalances (RUs), are evaluated experimentally using model-based methodology. A test rig was developed and used for experimentation in which different levels of misalignment was introduced. After estimating the MFPs, then the accuracy was checked through an impact test on the rotor test rig. The effect of different levels of misalignments on estimated parameters was studied.
\end{abstract}

Keywords. Turbo-generator; coupling; misalignment; dynamic parameters; experimental investigation.

\section{Introduction}

Rotor trains are commonly and extensively employed in the industries such as machine tools, automobiles, aeroplanes, rockets, ships, submarines, power plants, household appliances and medical tools. The most commonly employed rotating machines are turbines, generators, compressors, fans, centrifuges, pumps, motors, engines and machine tools. A turbo-generator system consists of multiple shafts supported on flexible bearings and held with the help of coupling (either rigid or flexible). Such dynamic systems need precise and reliable prediction of the dynamic feature of their crucial components and identification of associated fault parameters. Identification of multiple fault parameters (MFPs) of these systems is the top priority of researchers in this area.

With the state-of-the-art method in RU estimation [1-7], it is clear that the estimation of RUs in flexible rotor systems is an age-old problem among various kinds of fault in rotating machinery (e.g. residual unbalances, misalignments, shaft cracks, bend in a shaft, loose components, bearing and gear faults, rotor-stator rubs and the motor mechanical and electrical faults). With the existing procedures, it is possible to estimate the unbalance quite accurately. However, the present scenario requires fewer test runs, measurements, balancing planes and optimum

*For correspondence placement of sensors to estimate unbalances in large turbogenerator systems where accessibility is limited and downtime very expensive [4, 7-11].

The method proposed by Lees and Friswell [12] was experimentally validated by Edwards et al [8] to identify the amount of unbalance in a rotating machine by using a single rundown data. Gibbons [4] presented a review on different balancing techniques developed and actively controlled vibration of the rotating machinery. A modelbased approach to evaluate unbalances present in a rotor system was attempted by Jain and Kundra [9], where the fault was modelled as an equivalent load. Naucler and Soderstrom [13] estimated the unbalance in rotating machinery based on the influence coefficient method. In their regression model, unknown parameters were entered as non-linear terms, which were reformulated by keeping the input parameters linear. Sudhakar and Sekhar [10] presented an identification technique based on equivalent load minimisation to reduce the estimation error. They used the modal expansion technique to avoid measurements at all degrees of freedom (DOFs). The finite element (FE) modelling with four DOFs per node was considered to derive the system frequency equation.

A rotor fault, referred to as misalignment, is significant in a rotor train at coupling and bearing locations and wellestablished problem apart from residual unbalances. Detection of misalignment and diagnosis has not attracted many researchers, and its estimation is still an emerging 
and challenging area of research. Perfect alignment of rotor trains is critical in any rotating machinery, because misalignment leads to unwanted vibration at critical locations (i.e. bearing and coupling).

Misalignment of the rotor system received attention in late 1970s. Gibbons [14] analysed the effect of misalignment at the coupling in terms of misalignment forces; however, vibration signature of misaligned rotor was not discussed in his work. Since then, this topic has become a significant focal point among the practitioners and researchers of rotor dynamics. An analytical approach to model a turbo-generator system with misalignment was proposed in $[15,16]$. In this investigation, self-designed coupling was compared with the commercially used helical coupling, and result obtained theoretically was validated experimentally under the same misalignment and unbalance conditions. The vibration signal of a misaligned rotor system was obtained analytically by Sekhar and Prabhu [17] and reported that the characteristic signature of the misaligned shaft was present in the system as $2 \times$ vibration responses. A rotor-bearing system joined with coupling under misalignment condition was analysed by Lee and Lee [18], who reported that as the amount of angular misalignment increased, the associated natural frequency increased linearly. However, the impact of parallel misalignment on natural frequency was negligible.

A non-linear behaviour of a misaligned rotor system was analysed and non-linear equations of motion was developed for the misaligned systems by researchers $[19,20]$. However, in the result they reported that the $2 \times$ vibration component was absent under misalignment conditions. Prabhakar et al [21] analysed transient conditions of a rotor system for the crack and the coupling misalignment and concluded that both rotor faults depicted similar symptoms. Sinha et al [22] suggested an approach for the simultaneous estimation of misalignment and rotor unbalance along with foundation parameters. Pennacchi and Vania [23] described the orbit shape and model-based technique to identify coupling misalignment. Equivalent bending moments, which enabled the shaft experimental vibrations to be simulated, were identified using a model-based identification method.

System equation for a rotor train connected together with a rigid coupling was developed by Lees [24]. The effect of misalignment was presented in the form of coupling of the torsional and bending motions. Types of misalignment and its influence on the rotor behaviour were investigated by Patel and Darpe [25]. Jalan and Mohanty [26] developed a model-based fault diagnosis technique for a rotor system using a residual generation approach. Sarkar et al [27] performed FE analysis of misaligned rotors mounted on oilfilm bearings. They proposed a method for computing displacement-dependent stiffness terms from the experimental static load displacement data.

A flexible coupling-rotor system was modelled by Ganesan and Padmanabhan [28] for parametric excitation under the misalignment condition. The responses obtained indicate the effect of parametric excitation at one-fourth, one-third, and one-half of the principal parametric resonance. Tadeo et al [29] performed the dynamic characterisation of a flexible coupling that connects two co-axial shafts. The literature on coupling misalignment mainly focuses on couplings modelling and estimation of misalignment dynamic parameters, qualitatively. On the other hand, only a few researchers have made efforts to estimate misalignment parameters, either numerically or experimentally.

Dynamic parameters of bearings and seals impart a vital role in the estimation of performance of complete turbogenerator systems. Because of the complexity in achieving the actual test conditions, well-evolved theoretical and numerical models are unable to give satisfactory results $[30,31]$. Estimation of misalignment parameters in addition to the distinct parameters of rotor faults is advantageous, in a way it reduces modelling inaccuracy of bearings.

In the current research, the trend is towards the characterisation of model parameters of multiple machine-element faults from experimental measurements. In the area of model-based estimation of multi-class faults, few researchers have investigated dissimilar class of flaws simultaneously, or even identical flaws at several locations in rotor systems. Identification techniques of multiple faults are highly complex in comparison with single fault because the number of unknown fault parameters increases drastically that leads to ill-conditioning of the regression matrix.

Sinha et al [32] proposed a methodology to evaluate the foundation and unbalance parameters of the flexible rotating machinery by dividing the whole frequency range into different frequency bands. Bachschmid et al [33] experimentally validated the multi-fault identification algorithm based on least-squares technique. They considered different rotor fault models in this analysis. An algorithm was developed to estimate flaws in massive turbo machineries [34]. By means of equivalent force systems, the effect of faults was modelled and an identification technique was developed.

Ping and Guang [35] used the blind-source separation technique to develop an algorithm for multi-fault diagnosis of rotor system. This technique was mainly used to segregate different vibrational characteristics developed due to several flaws present in the machinery. Singh and Tiwari [36] evolved a novel estimation technique to estimate the presence of multiple cracks. The proposed methodology was also able to quantify the depth and angular location of the crack on non-rotating shaft system. Recently, Yang [37] proposed a scheme that could compute the stiffness perturbation parameter without any higher-order sensitivity analysis or iteration. Several papers mentioned earlier have modelled the fault as an equivalent force system that often leads to erroneous results due to the non-unique solution. Thus, the intension of the current research is to evolve a model-based identification algorithm to estimate multiple 
machine-element faults experimentally focusing on the effect of misalignment.

Lal and Tiwari [38] developed an identification algorithm to evaluate BCDPs and RUs for rigid rotor balancing at predefined planes. A major practical limitation of the work was that the rotor was modelled as a rigid rotor. This method was later extended for a more practical case, that is, the system was made flexible, and a more practical approach, such as FEM, was used to derive equations of motion [39]. Based on their work, [38], Lal and Tiwari [40] presented an experimental work for rigid rotor case. Experimental investigation faces a few challenges in the measurement of rotational DOFs, especially at coupling locations. The present work addresses these and other issues related to practical implementation of multiple fault identification algorithms [39].

The current research focuses on experimental investigation of multi-class faults present in rotor system in terms of a system's dynamic parameter evaluation. Experiments were conducted on a self-developed test rig in the vibration and acoustics laboratory at IIT Guwahati. The forced response of shafts was measured only at bearing locations at several rotor speeds to estimate these parameters. Estimates of BCDPs and RUs were found to be consistent with different sets of measurements for no misalignment conditions. The effect of different misalignment conditions on the estimates was also analysed, and it was found that the natural frequency of the system splits due to such misalignments.

\section{Identification algorithm}

For completeness, the identification algorithm developed by Lal and Tiwari [39] to quantitatively estimate dynamic parameters of bearing and coupling together with residual unbalances (RUs) has been presented briefly in this section. The algorithm uses shaft deflections at four bearing locations in two orthogonal directions at several excitation frequencies (i.e. spin speeds).

Combined system equation could be represented as

$$
[M]\{\ddot{\eta}\}+[C]\{\dot{\eta}\}+[K]\{\eta\}=\{f(t)\}
$$

where $[M],[C]$ and $[K]$ are the mass, damping and stiffness matrices, respectively; $\{\eta\}$ and $\{f\}$ are the displacement and force vectors. Matrices with the Timoshenko beam model are given in Appendix A. Here, force and displacement could be represented as $\{f(t)\}=\{\bar{f}\} e^{\mathrm{j} \omega t}$ and $\{\eta(t)\}=\{\bar{\eta}\} e^{\mathrm{j} \omega t}$ respectively. On substituting force and displacement expressions into Eq. (1), we obtain

$$
\left([K]+\mathrm{j} \omega[C]-\omega^{2}[M]\right)\{\bar{\eta}\}=\{\bar{f}\}
$$

The complex response at several spin speeds of the system can be obtained from Eq. (2) for known rotor dynamic parameters and unbalance information. A high- frequency condensation scheme [41] has been used to eliminate immeasurable DOFs that exclude linear DOFs at bearing location and includes all other linear and angular DOFs. The advantage of this condensation is that it can be applied to eliminate those DOFs also at which parameters are to be estimated, for example, coupling DOFs. Eq. (2) could be reshuffled such that all the parameters to be estimated are stacked in a left-hand side vector and all known parameters are stacked in a right-hand side vector. After reshuffling, the desired form could be obtained as

$$
[A(\omega)]_{16 \times 46}\{X\}_{46 \times 1}=\{B(\omega)\}_{16 \times 1}
$$

with

$$
\begin{aligned}
& \{X\}_{46 \times 1}=\left\{k_{x x}^{B_{1}}, k_{x y}^{B_{1}}, k_{y x}^{B_{1}}, k_{y y}^{B_{1}}, k_{x x}^{B_{2}}, k_{x y}^{B_{2}}, k_{y x}^{B_{2}}, k_{y y}^{B_{2}}, k_{x x}^{B_{3}}, k_{x y}^{B_{3}},\right. \\
& k_{y x}^{B_{3}}, k_{y y}^{B_{3}}, k_{x x}^{B_{4}}, k_{x y}^{B_{4}}, k_{y x}^{B_{4}}, k_{y y}^{B_{4}}, k_{x x}^{C}, k_{x y}^{C}, k_{y x}^{C}, k_{y y}^{C}, k_{\varphi_{x}}^{C}, k_{\varphi_{y}}^{C}, c_{x x}^{B_{1}}, c_{x y}^{B_{1}}, \\
& c_{y x}^{B_{1}}, c_{y y}^{B_{1}}, c_{x x}^{B_{2}}, c_{x y}^{B_{2}}, c_{y x}^{B_{2}}, c_{y y}^{B_{2}}, c_{x x}^{B_{3}}, c_{x y}^{B_{3}}, c_{y x}^{B_{3}}, c_{y y}^{B_{3}}, c_{x x}^{B_{4}}, c_{x y}^{B_{4}}, c_{y x}^{B_{4}}, c_{y y}^{B_{4}}, \\
& \left.c_{x x}^{C}, c_{x y}^{C}, c_{y x}^{C}, c_{y y}^{C}, U_{x_{1}}^{r}, U_{x_{1}}^{i}, U_{x_{2}}^{r}, U_{x 2}^{i}\right\}^{T} \\
& {[A]_{16 \times 46}=\left[\begin{array}{lll}
{\left[k^{r}\right]_{16 \times 22}} & {\left[c^{r}\right]_{16 \times 20}} & {\left[u^{r}\right]_{16 \times 4}}
\end{array}\right]_{16 \times 46}}
\end{aligned}
$$

where $\left[k^{r}\right],\left[c^{r}\right]$ and $\left[u^{r}\right]$ are individual regression matrices for the stiffness, damping and unbalance, respectively, that are contributing to obtain final regression matrix. Details of these matrices are given in [39]. On segregating the real and imaginary component from Eq. (3), it could be written as

$$
[A(\omega)]_{32 \times 46}\{X\}_{46 \times 1}=\{B(\omega)\}_{32 \times 1}
$$

From Eq. (4), it could be seen that the number of unknowns are more than the number of equations so this is a case of underdetermined system. Hence, it is required to make the system determinate or over-determinate to estimate all the unknown parameters. It could also be seen from Eq. (4) that two independent sets of measurements are required to make the system determinate and could be written as

$$
[A(\omega)]_{64 \times 46}\{X\}_{46 \times 1}=\{B(\omega)\}_{64 \times 1}
$$

Equation (5) is the desired regression form to obtain the BCDPs and RUs with the help of least-squares fit as follows:

$$
\{X\}_{46 \times 1}=\left([A(\omega)]_{46 \times 64}^{T}[A(\omega)]_{64 \times 46}\right)_{46 \times 46}^{-1}[A(\omega)]_{46 \times 64}^{T}\{B(\omega)\}_{64 \times 1}
$$

In this study, the developed algorithm is validated with experiments in a real test rig. The procedure followed to capture measurement signals and post-processing of signals is explained in the subsequent section.

\section{Experimental setup}

In the present section, the experimental investigation of the multiple faults identification algorithm, briefed in the previous section, would be performed in a laboratory set-up. 


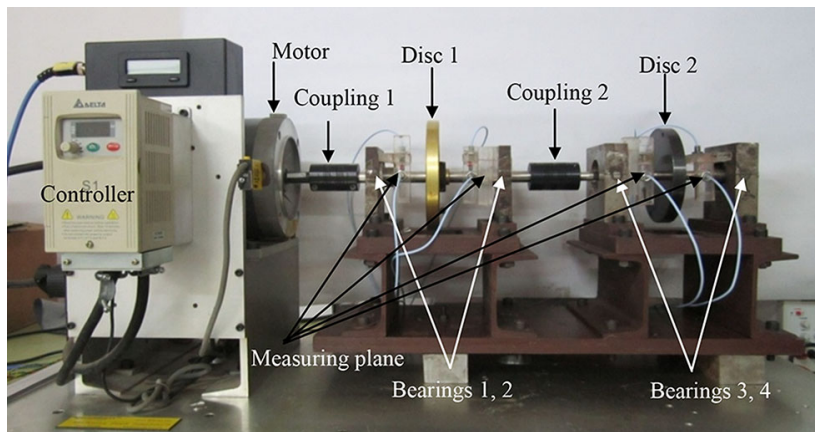

Figure 1. Pictorial view of experimental test rig.

\subsection{The description of rotor test rig and support conditions}

As shown in figure 1, a flexible coupling (Coupling 2) is used to connect two shafts, and two deep-grove ball bearings at ends are used to mount each shaft. Between the bearing outer ring and housing bore, a thin soft material padding was provided to increase the damping effect and decrease the stiffening effect. A hollow hub made of mild steel was prepared and press-fitted into the bearing innerrace to accommodate the shaft. Threaded holes were made on the hub for easy mounting/dismounting and to adjust the axial position of the shaft. The rotor system via a flexible coupling (Coupling 1) was powered through a $0.55 \mathrm{~kW}$

Table 1. Specification of test rig.

\begin{tabular}{lcccccc}
\hline S.N. & Item no. & Length/width $(\mathrm{m})$ & Diameter $(\mathrm{m})$ & Density $\left(\mathrm{kg} / \mathrm{m}^{3}\right)$ & Mass $(\mathrm{kg})$ & Diametral mass moment of inertia $\left(\mathrm{kg}-\mathrm{m}^{2}\right)$ \\
\hline 1 & Shaft 1 & 0.27 & 0.012 & 7740 & 0.39 & $2.39 \times 10^{-3}$ \\
2 & Shaft 2 & 0.27 & 0.016 & 7740 & 0.32 & $1.90 \times 10^{-3}$ \\
3 & Disc 1 & 0.01 & 0.010 & 2600 & 0.66 & $8.25 \times 10^{-6}$ \\
4 & Disc 2 & 0.01 & 0.012 & 7800 & 1.01 & $18.20 \times 10^{-6}$ \\
\hline
\end{tabular}

Table 2. Bearing specifications.

\begin{tabular}{lccccc}
\hline S.N. & Bearing location & Bearing no. & Bore diameter $(\mathrm{mm})$ & Outer diameter (mm) & Width (mm) \\
\hline 1 & 1 and 2 & 6005 ZNR (SKF) & 25 & 47 & 12 \\
2 & 3 and 4 & 6004 ZNR (SKF) & 20 & 42 & 12 \\
\hline
\end{tabular}

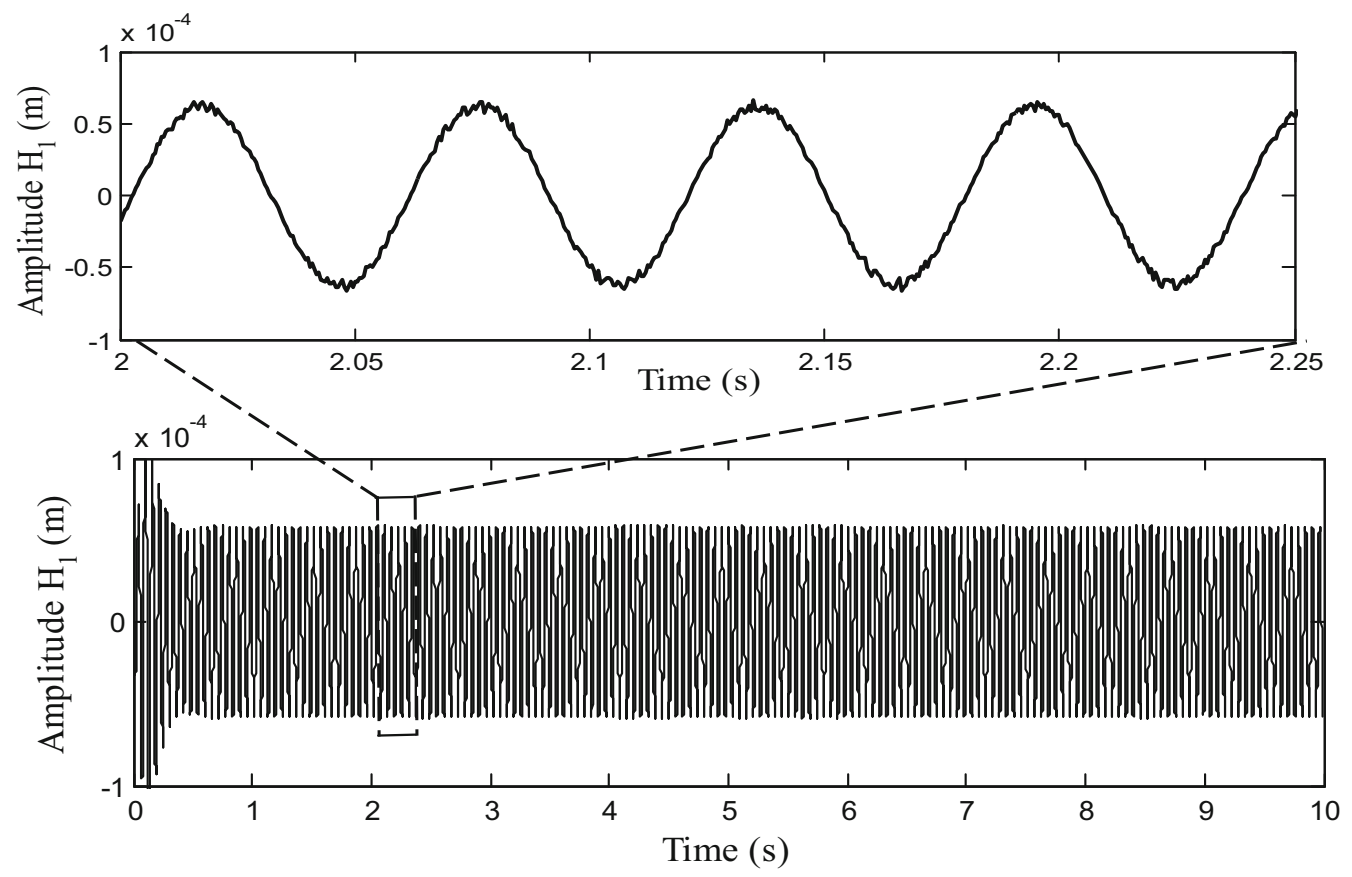

Figure 2. A sample time history data of the horizontal direction response at bearing location 1 at $17 \mathrm{~Hz}$. 


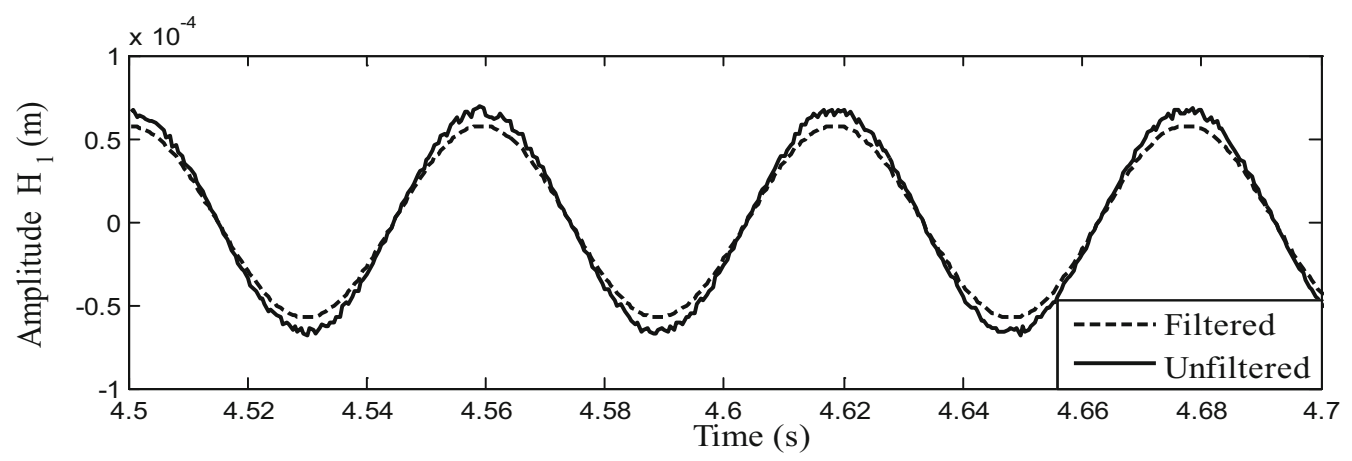

Figure 3. The filtered and unfiltered signal for the sample time history of figure 2 .

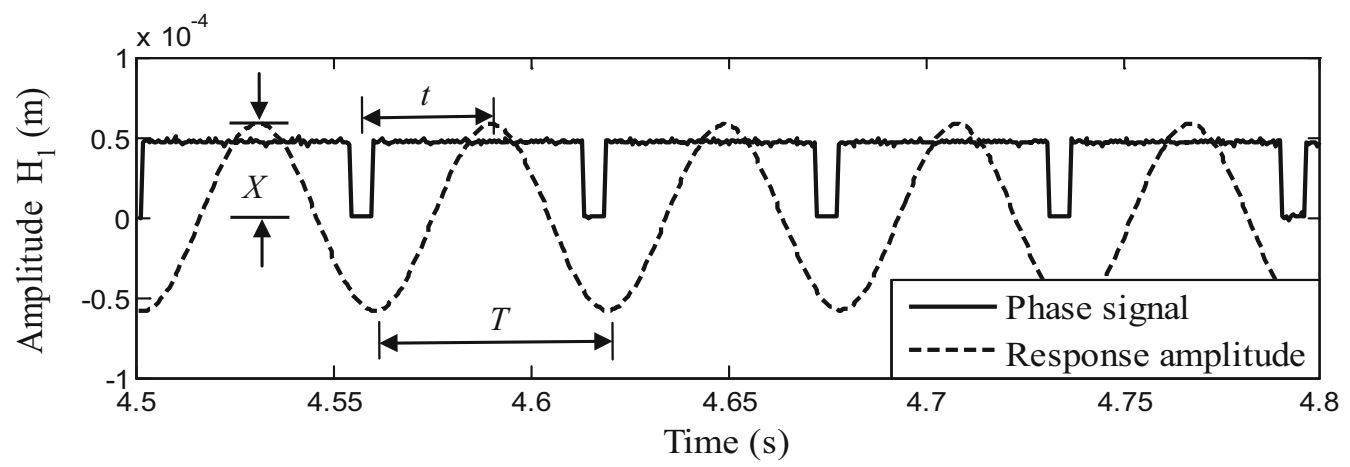

Figure 4. A time history response for bearing 1 at operating speed of $17 \mathrm{~Hz}$ with a phase signal.

(0.75 HP) DC motor source that could be operated at variable speeds by changing the speed through its controller (i.e. Delta make variable frequency drive). Specifications of rotor test rig are given in table 1 . Relatively heavy discs were symmetrically placed on shafts and, consequently, the unbalance was expected to be concentrated at disc locations only. Bearing specifications are given in table 2. Experimental procedure is discussed in the subsequent subsection.

\subsection{Experimental procedure}

With the help of a dial indicator, best achievable alignment at both the coupling locations is achieved at the beginning of experiments. The least count of dial indicator was $1 \mu \mathrm{m}$. The present identification algorithm works on forced vibration data (e.g. at discrete speeds or the run-up and rundown data). The experimental procedures followed to obtain the desired response signal followed by signal processing are listed as follows.

1. The LabView ${ }^{\mathrm{TM}}$ was configured to capture time domain signals in order to ensure working of all nine input channels (eight displacement signals and one reference signal) of the DAQ. The experimental set-up was done to measure displacement signals at a particular speed of the rotor.
2. As shown in figure 1, displacement sensors (eddy current sensor) are used near the bearing locations (measuring planes) in two orthogonal directions to capture the displacement signal in a time domain followed by an amplifier to amplify the signal and obtained in a digitised form as an output of DAQ. As a trial-run horizontal response at bearing location 1 is obtained in time domain at spin speed of $17 \mathrm{~Hz}$, refer figure 2 .

3. In a personal computer, the digitised measurement data were stored for post-processing, recorded at sampling frequency of $1 \mathrm{kHz}$ at eight different spin speeds of the rotor (i.e. $17 \mathrm{~Hz}, 21 \mathrm{~Hz}, 25 \mathrm{~Hz}, 29 \mathrm{~Hz}, 31 \mathrm{~Hz}, 33 \mathrm{~Hz}, 37$ $\mathrm{Hz}$ and $41 \mathrm{~Hz}$ ).

4. Electronic instruments are the sources of noise that affect the response signal, which is generally contaminated with DC components. Hence, the measured response signal is passed through a digital filter to overcome the noise effect from the signal.

5. Filter was designed using the 'Filter design and analysis tool' from the MATLAB toolbox. A band-pass filter was designed using the Butterworth method. The sampling frequency was obtained from the measured signal $1 \mathrm{kHz}$ and cut-off frequencies were selected based on the excitation frequency (i.e. $\pm 2 \mathrm{~Hz}$ of the excitation frequency). The sample unfiltered signals (figure 2) was filtered and shown in figure 3. A decrease in the 
amplitude is observed; although, no phase shift is observed between the filtered and unfiltered signals.

6. A MATLAB code was written to obtain the maxima, minima and time period from the filtered response signal plotted in time domain. Once a set of maxima, minima and time period is obtained, the filtered response amplitude, $X$, and the phase angle $(\phi)$ is calculated (refer figure 4) as follows: measurements at eight independent spin speeds, i.e. $\omega_{1}=17$ $\mathrm{Hz}, \omega_{2}=21 \mathrm{~Hz}, \omega_{3}=25 \mathrm{~Hz}, \omega_{4}=29 \mathrm{~Hz}, \omega_{5}=31 \mathrm{~Hz}, \omega_{6}=$ $33 \mathrm{~Hz}, \omega_{7}=37 \mathrm{~Hz}$ and $\omega_{8}=41 \mathrm{~Hz}$. The repeatability of the estimates was checked with three different such sets of measured data. Table 5 shows experimentally estimated BCDPs and RUs. It could be observed that most of the estimated stiffness, damping and unbalance parameters were consistent even with different sets of measurements.

$$
X=\frac{\text { Maxima in response time history }- \text { Minima in response time history }}{2}(\mathrm{~mm})
$$

$$
\phi=\frac{t}{T} \times 360(\text { degree })
$$

The phase of the displacement was obtained with respect to a particular phaser signal for all response data measured at several independent rotor spin speeds. After obtaining the response amplitude and phase from Eqs. (7) and (8), the real part $(X \cos \phi)$ and the imaginary part $(X \sin \phi)$ of the response could be obtained.

7. Sample measured responses (in complex form with the real and imaginary parts that contain both magnitude and phase of responses) are given in table 3, for a horizontal response $H_{1}$, at all the eight independent operating speeds. Subscripts $r$ and $i$ represent the real and imaginary parts, respectively, of the response $H_{1}$.

8. This real and imaginary forms of response data obtained in time domain is converted into frequency domain data that is required in the present identification algorithm (Eq. (6)).

This measurement procedure with and without misalignment conditions has been repeated to check the recurrence of the identification algorithm. Different misalignment conditions are presented in table 4.

\subsection{Parameter estimation without misalignment}

Complex frequency response signal obtained experimentally in the previous section is used in Eq. (6) to evaluate the BCDPs and RUs. Here the estimation was performed with

\subsection{Validation of estimated parameters without misalignment}

The evaluated system dynamic parameters were validated with the help of impact test on the rig and measuring the free vibration data. The following steps were involved in the overall procedure.

1. The LabView ${ }^{\mathrm{TM}}$ was configured to capture frequency domain signals.

2. After ensuring the proper working of the entire channel, the frequency capture module of the DAQ is test the standard impact to identify the natural frequency of the system. To capture this signal, the accelerometer was mounted over the bearing housing near Coupling 2 .

3. First, both couplings (i.e. couplings 1 and 2) were removed, and an impact test was performed for individual rotor systems (i.e. rotors 1 and 2). A typical

Table 4. Parameters of Misalignment.

\begin{tabular}{lccc} 
S. N. & Cases of misalignment & Sets & $\begin{array}{c}\text { Amount of misalignment } \\
\text { (degree, mm) }\end{array}$ \\
\hline 1 & Pure angular & Set $X_{1}$ & $\Delta \Phi=0.16, \Delta \varepsilon=0.0$ \\
& & Set $X_{2}$ & $\Delta \Phi=0.32, \Delta \varepsilon=0.0$ \\
2 & Pure parallel & Set $Y_{1}$ & $\Delta \Phi=0.00, \Delta \varepsilon=0.5$ \\
& Set $Y_{2}$ & $\Delta \Phi=0.00, \Delta \varepsilon=1.0$ \\
3 & Combination of both & Set $Z_{1}$ & $\Delta \Phi=0.16, \Delta \varepsilon=0.5$ \\
& & Set $Z_{2}$ & $\Delta \Phi=0.32, \Delta \varepsilon=1.0$ \\
\hline
\end{tabular}

\begin{tabular}{|c|c|c|c|c|c|c|c|c|c|}
\hline \multirow{2}{*}{$\begin{array}{l}\text { S. } \\
\text { N. }\end{array}$} & \multirow{2}{*}{$\begin{array}{c}\text { Response } \\
\text { components }(\mathrm{m})\end{array}$} & \multicolumn{8}{|c|}{ Response components $(\mathrm{m})$ at operating speeds $(\mathrm{Hz})$} \\
\hline & & 17 & 21 & 25 & 29 & 31 & 33 & 37 & 41 \\
\hline 1 & $H_{1 r}=X \cos \phi$ & $5.57 \times 10^{-5}$ & $-4.63 \times 10^{-5}$ & $1.17 \times 10^{-5}$ & $4.04 \times 10^{-5}$ & $4.11 \times 10^{-5}$ & $4.77 \times 10^{-5}$ & $8.91 \times 10^{-6}$ & $-5.82 \times 10^{-5}$ \\
\hline 2 & $H_{1 i}=X \sin \phi$ & $-3.57 \times 10^{-6}$ & $3.43 \times 10^{-5}$ & $5.29 \times 10^{-5}$ & $2.99 \times 10^{-5}$ & $-4.67 \times 10^{-5}$ & $-4.57 \times 10^{-5}$ & $6.45 \times 10^{-5}$ & $-3.77 \times 10^{-5}$ \\
\hline
\end{tabular}

Table 3. A sample stored response (in complex form with magnitude and phase information) at different operating speed. 
Table 5. Estimated stiffness, damping and unbalance parameters.

\begin{tabular}{|c|c|c|c|c|c|c|c|c|c|c|c|}
\hline $\begin{array}{l}\text { Para } \\
\text { meters }\end{array}$ & $\begin{array}{c}\text { Set } 1 \\
(\mathrm{kN} / \mathrm{m})\end{array}$ & $\begin{array}{c}\text { Set } 2 \\
(\mathrm{kN} / \mathrm{m})\end{array}$ & $\begin{array}{c}\text { Set } 3 \\
(\mathrm{kN} / \mathrm{m})\end{array}$ & $\begin{array}{c}\text { Para } \\
\text { meters }\end{array}$ & $\begin{array}{c}\text { Set } 1 \\
(\mathrm{Ns} / \mathrm{m})\end{array}$ & $\begin{array}{c}\text { Set } 2 \\
(\mathrm{Ns} / \mathrm{m})\end{array}$ & $\begin{array}{c}\text { Set } 3 \\
(\mathrm{Ns} / \mathrm{m})\end{array}$ & $\begin{array}{c}\text { Para } \\
\text { meters }\end{array}$ & $\begin{array}{l}\text { Set } 1 \\
(\mathrm{~kg}-\mathrm{m})\end{array}$ & $\begin{array}{c}\text { Set } 2 \\
(\mathrm{~kg}-\mathrm{m})\end{array}$ & $\begin{array}{l}\text { Set } 3 \\
(\mathrm{~kg}-\mathrm{m})\end{array}$ \\
\hline$\overline{k_{x x}^{B_{1}}}$ & 352 & 352 & 353 & $c_{x x}^{B_{1}}$ & 262 & 262 & 261 & $U_{x_{1}}^{r}$ & 0.0042 & 0.0042 & 0.0041 \\
\hline$k_{x y}^{B_{1}}$ & 41 & 42 & 43 & $c_{x y}^{B_{1}}$ & 52 & 51 & 50 & $U_{x_{1}}^{i}$ & 0.0034 & 0.0035 & 0.0035 \\
\hline$k_{y x}^{B_{1}}$ & 42 & 41 & 43 & $c_{y x}^{B_{1}}$ & 50 & 50 & 51 & $U_{x_{2}}^{r}$ & 0.0027 & 0.0026 & 0.0028 \\
\hline$k_{y y}^{B_{1}}$ & 349 & 350 & 351 & $c_{y y}^{B_{1}}$ & 258 & 258 & 259 & $U_{x_{2}}^{i}$ & 0.0061 & 0.006 & 0.0062 \\
\hline$k_{x x}^{B_{2}}$ & 381 & 380 & 381 & $c_{x x}^{B_{2}}$ & 316 & 317 & 318 & & & & \\
\hline $\begin{array}{r}u x \\
k_{x y}^{B_{2}}\end{array}$ & 28 & 28 & 29 & $c_{x y}^{B_{2}}$ & 23 & 24 & 25 & & & & \\
\hline$k_{y x}^{B_{2}}$ & 29 & 30 & 31 & $c_{v x}^{B_{2}}$ & 26 & 27 & 29 & & & & \\
\hline$k_{y y}^{B_{2}}$ & 384 & 383 & 385 & $c_{y y}^{B_{2}}$ & 315 & 315 & 317 & & & & \\
\hline$k_{x x}^{B_{3}}$ & 431 & 430 & 429 & $c_{x x}^{B_{3}}$ & 309 & 310 & 312 & & & & \\
\hline $\begin{array}{r}{ }_{1} \\
k_{x y}^{B_{3}}\end{array}$ & 21 & 21 & 22 & $c_{x y}^{B_{3}}$ & 39 & 39 & 40 & & & & \\
\hline$k_{y x}^{B_{3}}$ & 24 & 23 & 25 & $c_{y x}^{B_{3}}$ & 40 & 41 & 42 & & & & \\
\hline$k_{y y}^{B_{3}}$ & 430 & 430 & 431 & $c_{y y}^{B_{3}}$ & 311 & 310 & 310 & & & & \\
\hline$k_{x x}^{B_{4}}$ & 299 & 300 & 301 & $c_{x x}^{B_{4}}$ & 280 & 280 & 282 & & & & \\
\hline$k_{x y}^{B_{4}}$ & 55 & 55 & 56 & $c_{x y}^{B_{4}}$ & 28 & 29 & 30 & & & & \\
\hline$k_{y x}^{B_{4}}$ & 53 & 54 & 55 & $c_{y x}^{B_{4}}$ & 28 & 30 & 31 & & & & \\
\hline$k_{y y}^{B_{4}}$ & 296 & 297 & 297 & $c_{y y}^{B_{4}}$ & 283 & 284 & 285 & & & & \\
\hline$k_{x x}^{C}$ & 268 & 267 & 269 & $c_{x x}^{C}$ & 205 & 204 & 202 & & & & \\
\hline$k_{x y}^{C}$ & 40 & 41 & 42 & $c_{x y}^{C}$ & 17 & 18 & 21 & & & & \\
\hline$k_{y x}^{C}$ & 39 & 40 & 40 & $c_{y x}^{C}$ & 19 & 20 & 20 & & & & \\
\hline$k_{y y}^{C}$ & 269 & 269 & 270 & $c_{y y}^{C}$ & 205 & 203 & 202 & & & & \\
\hline$k_{\varphi_{x}}^{C}$ & 140 & 141 & 142 & & & & & & & & \\
\hline$k_{\varphi_{y}}^{C}$ & 188 & 189 & 190 & & & & & & & & \\
\hline
\end{tabular}

frequency domain data is shown in figure 5 from the impact test on Rotor system 1 . In frequency domain data, a predominant peak was observed at $357 \mathrm{~Hz}$ corresponding to natural frequency of the system. The closed-form expression to obtain the natural frequency for the simply supported rotor (discrete case) is given in Appendix B and it gives the natural frequency for the present rotor configuration as $373 \mathrm{~Hz}$ (refer table B1). For approximation of the simply support and massless shaft, some deviation in the response is expected; since only rotor system 1 is considered for the present case, the identified peak from the impact test is the natural frequency of Rotor system 1.

4. Next, the impact test was performed on Rotor system 2 alone, and the FFT response plot is shown in figure 6, which indicates that the natural frequency is equal to 144 $\mathrm{Hz}$ and the natural frequency, as obtained from the closed-form solution for simply supported conditions, is obtained as $169 \mathrm{~Hz}$. It confirms that the identified peak from the impact test is the natural frequency of Rotor system 2.

5. Subsequently, the impact test was performed when both rotor systems, i.e. rotors 1 and 2, was joined by Coupling 2 alone with proper alignment. Figure 7 gives the FFT plot, and it indicates that natural frequencies of the rotor system are $149 \mathrm{~Hz}, 201 \mathrm{~Hz}$ and $362 \mathrm{~Hz}$. On comparison with previous frequencies, it could be observed that there is slight change in the frequencies from $144 \mathrm{~Hz}$ to $149 \mathrm{~Hz}$ and from $357 \mathrm{~Hz}$ to $362 \mathrm{~Hz}$. Apart from these frequencies, a new natural frequency is also introduced, due to the effect of coupling, at $201 \mathrm{~Hz}$.

6. An FE model with the Timoshenko beam theory and simply supported boundary conditions are developed to correlate results obtained experimentally. Modelling of Timoshenko beam is given in Appendix A. The coupling is modelled as flexible with 10 linearised stiffness and damping coefficients (refer Eq. (3)). The input data for the theoretical model are according to the experimental set-up and provided in tables 1 and 2 . From forced vibration responses that are given in figure $11 \mathrm{a}$, forward critical speeds are $155 \mathrm{~Hz}, 239 \mathrm{~Hz}$ and $419 \mathrm{~Hz}$. Because of simply supported conditions as well as gyroscopic effects, these critical speeds are higher than the corresponding natural frequencies (i.e. $155 \mathrm{~Hz}$ instead of $149 \mathrm{~Hz}, 239 \mathrm{~Hz}$ instead of $201 \mathrm{~Hz}$ and $419 \mathrm{~Hz}$ instead of $362 \mathrm{~Hz}$ ) in the actual test rig due to the flexibility of bearings and couplings and nonrotating condition of the impact test. After considering flexibility at bearings, the FE model's natural 


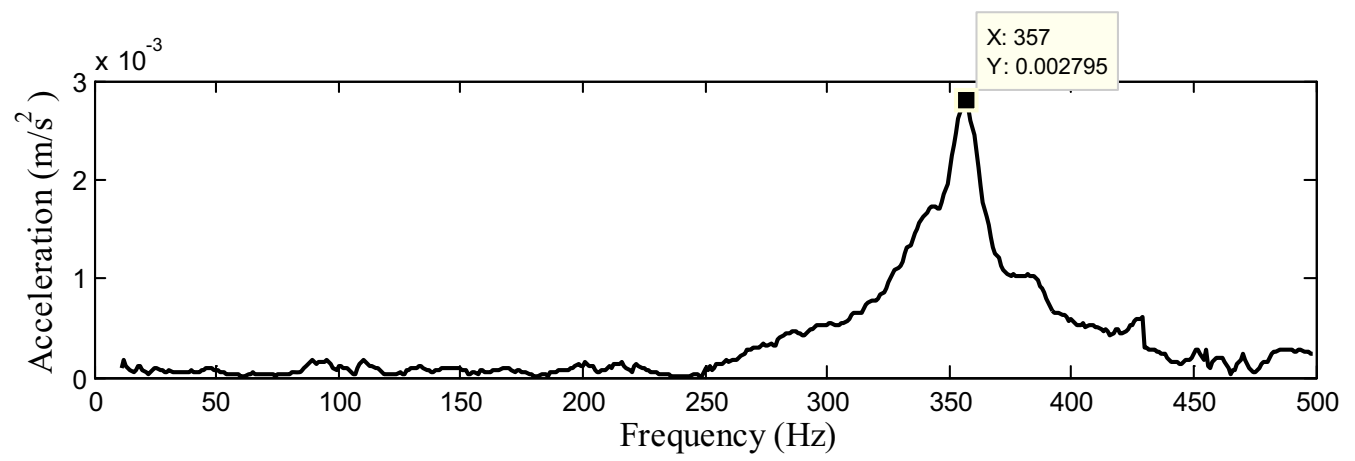

Figure 5. FFT of response of rotor system 1 (near motor end) without couplings.

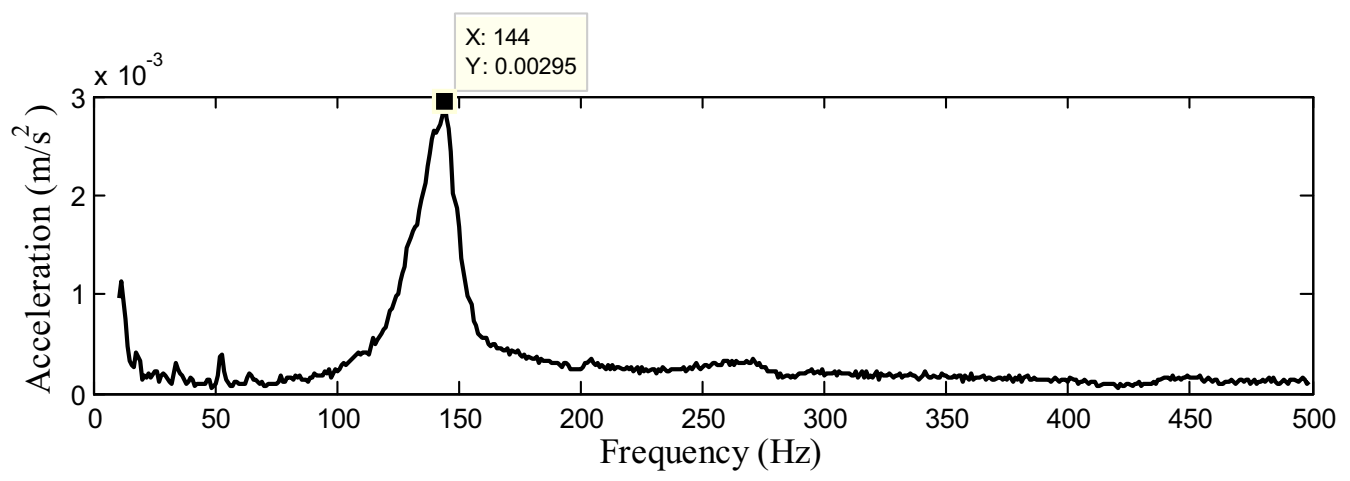

Figure 6. FFT of response of rotor system 2 (away from motor) without couplings.

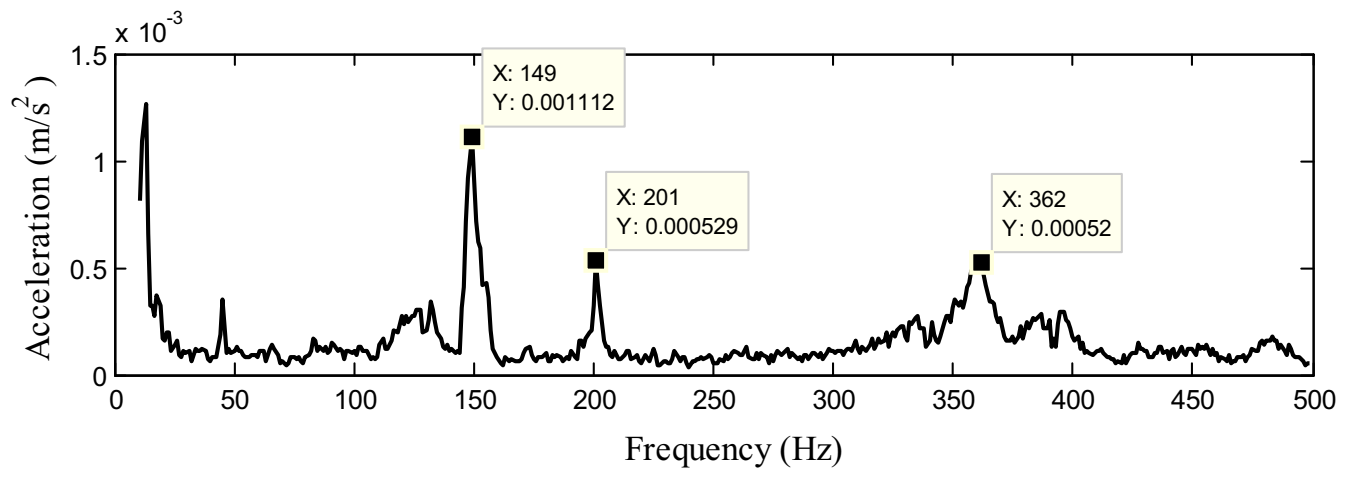

Figure 7. FFT of response of rotor systems 1 and 2 with only coupling 2.

frequencies are expected to be close to experimental natural frequencies.

7. Finally, Coupling 1 was also connected with Coupling 2 to see its effect on the rotor system natural frequencies. Figure 8 shows the FFT plot of the impact test for the assembled rotor system, and natural frequencies of the rotor system are $150 \mathrm{~Hz}, 203 \mathrm{~Hz}$ and $364 \mathrm{~Hz}$. In comparison with the previous case in which only coupling 2 was connected, there is a slight change in natural frequencies. The variations in natural frequencies for these two cases are $0.67 \%, 0.99 \%$ and $0.55 \%$ for the first, second and third natural frequencies, respectively. So the effect of Coupling 1 is negligible as compared to Coupling 2. 


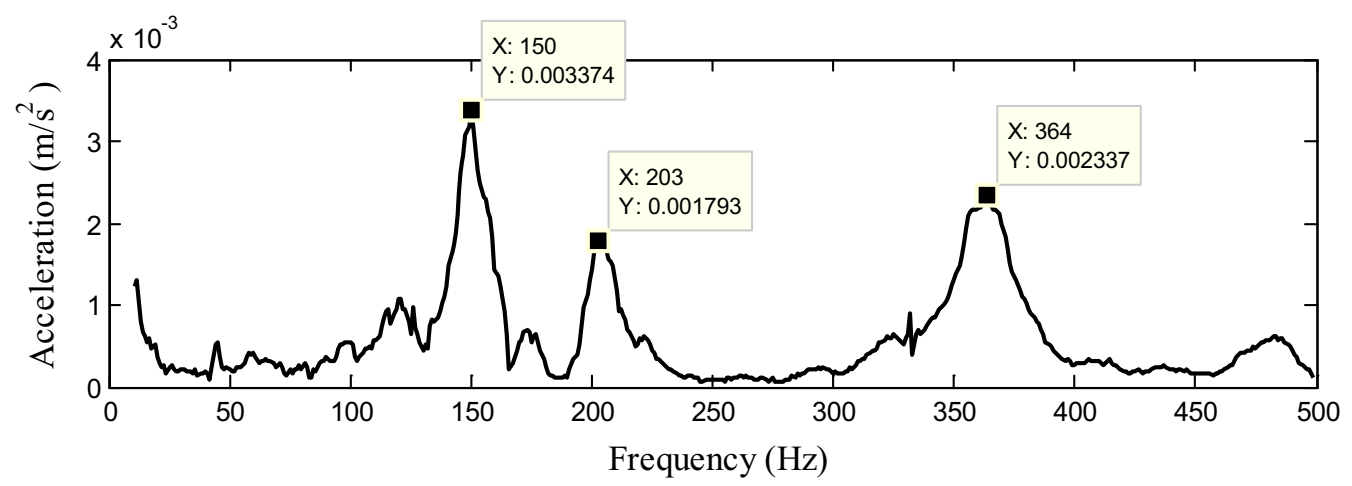

Figure 8. FFT of response of rotor systems 1 and 2 with both couplings 1 and 2 .

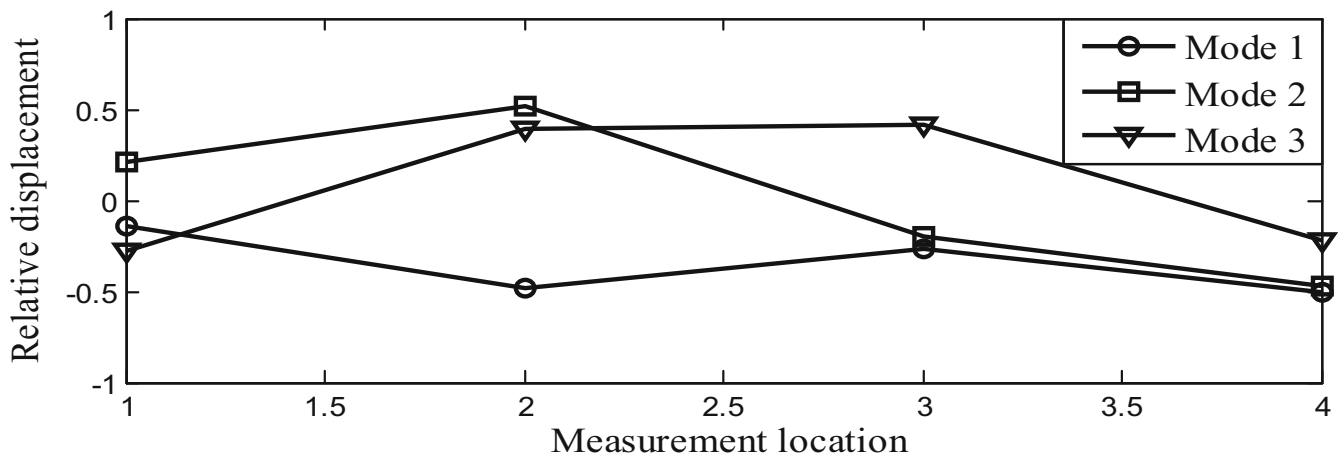

Figure 9. First three modes of the rotor system.

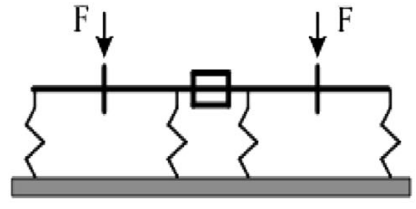

(a)

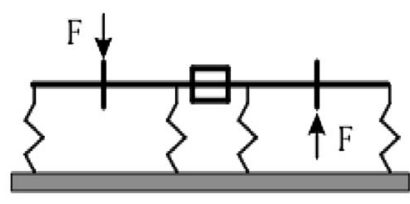

(b)

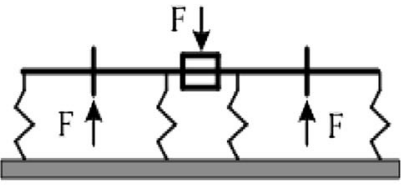

(c)

Figure 10. A schematic diagram of the experimental set-up with forcing directions to excite different modes of vibration (a) first mode, (b) second mode and (c) third mode.

The impact test was repeated several times by changing the impact location and the sensor position for checking the consistency of appearance of predominant peaks. The consistency of peaks was also checked by exciting a particular mode at a time by hitting the rotor at more than one place simultaneously (up to the third mode). An eigenvalue problem was solved to obtain the natural frequencies and mode shape of the system. The natural frequencies of the system are $\omega_{\mathrm{nf} 1}=155.7 \mathrm{~Hz}, \omega_{\mathrm{nf} 2}=239.3$ $\mathrm{Hz}$ and $\omega_{\mathrm{nf} 3}=419.9 \mathrm{~Hz}$. Figure 9 shows the mode shape of the complete rotor system. From figure 9, it could be analysed that Mode 1 has all displacements of the same sign (i.e. no node). It will occur if both the rotors are impacted downwards (or upwards) direction. Mode 2 has one node near the coupling location (either side has opposite sign). It will occur if both the shafts are impacted in opposite direction. Mode 3 has two nodes: one at each shaft. This will occur if both the shafts are impacted in the same direction but in opposite direction at the coupling. From this analysis, we can obtain the approximate location of forcing to get different modes of vibration in actual system. Figure 10 shows the schematic diagram of 


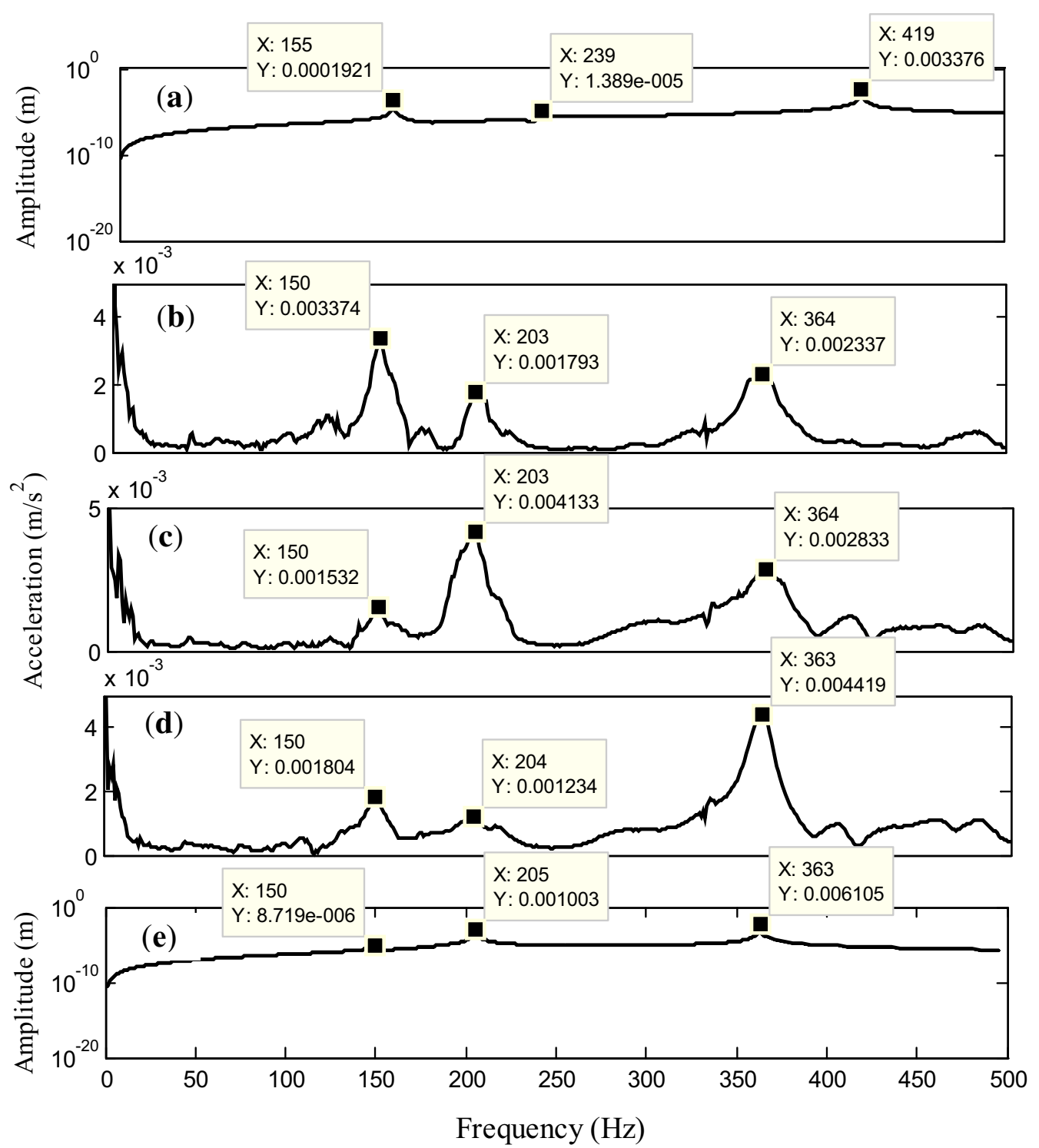

Figure 11. Comparison of natural frequencies (a) FE forced vibration solution with SSBC (critical speeds), (b) Impact test with 1st mode excitation, (c) impact test with 2nd mode excitation, (d) impact test with 3rd mode excitation and (e) updated FE model.

experimental set-up with forcing direction to get different modes of vibration. From figure $11 \mathrm{~b}-\mathrm{d}$, it can be seen that while trying to excite a particular mode (e.g. according to figure 10), that particular natural frequency (e.g. figure 11b) has a predominant peak as compared to other modes (e.g. figure $11 \mathrm{c}$ and d). This is valid for all modes excited, according to figure 10 . Since it is very difficult to purely excite one mode, contributions of other modes are also visible in these impact responses.

It is highly unlikely for experiments to imitate the endsupport conditions. In general, flexibility is observed at the support ends. For the rolling element bearing, theoretical formulae are available to obtain the stiffness approximately [42]; however, practical experiences show that they are not reliable.
After the estimation of BCDPs and RUs, this information were used to update the FE model. From figure 11e, one may analyse that critical speeds (more precisely the forward critical speed since the response is generated by unbalances) from the FE analysis are closely matching with natural frequencies obtained experimentally, i.e. figure $11 \mathrm{~b}-\mathrm{d}$. This is because the impact test was conducted while the rotor was stationary, whereas FE analysis considers its rotations also. However, the effect of gyroscopic couple is seen to be minimal in the experimental set-up since discs were placed at mid-spans of both shafts.

After the estimation of BCDPs and RUs, for without misalignment condition, the next step is the estimation of these parameters under misalignment conditions and discussed in the subsequent section. 


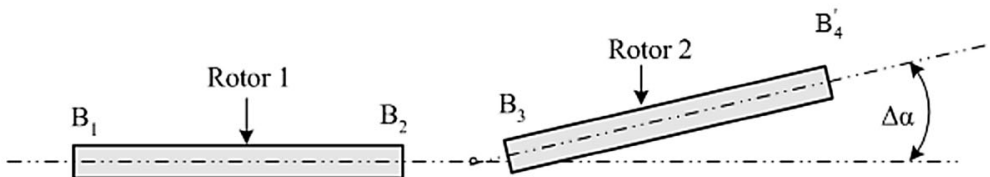

$\mathrm{B}_{4}$

(a)

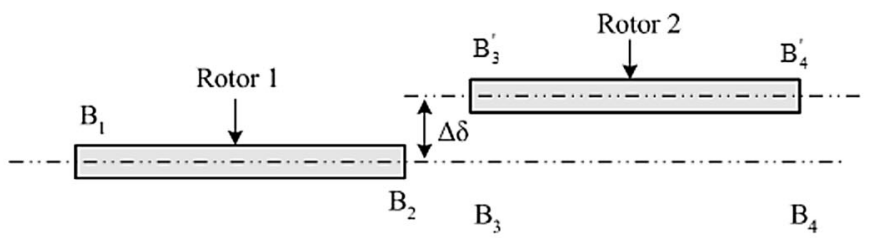

(b)

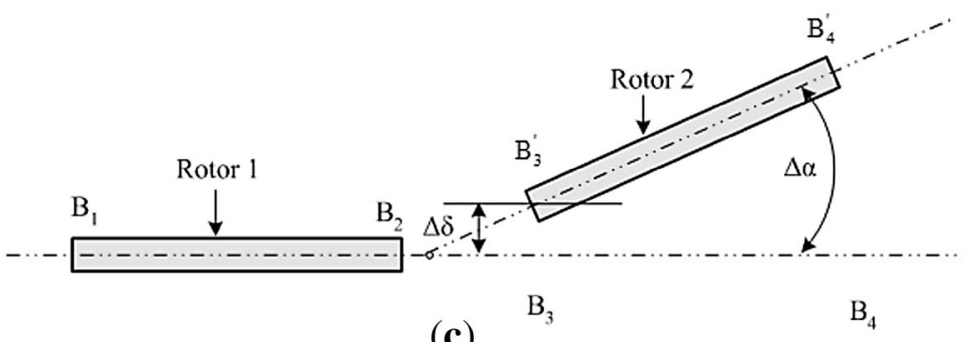

(c)

Figure 12. Classification of misalignment for (a) pure angular, (b) pure parallel, (c) combined angular and parallel.

\section{System dynamic parameter evaluation with different order of misalignment}

Here BCDPs and RUs are evaluated for different order of misalignment (refer table 4), where amount of misalignments are represented by angular, $\Delta \Phi$ and parallel, $\Delta \varepsilon$. For parallel and angular misalignment, aluminium sheets of known thickness were inserted below the bearing housings of Rotor 2 only. For the parallel misalignment in both bearing housings the same number of sheets were inserted and for the angular misalignment only in the bearing housing near Coupling 2 the sheets were inserted. For a combination of misalignments, different number of sheets in the two bearing housings was inserted in Rotor 2. The procedure to obtain different order of misalignments (angular, parallel and combined misalignment) is represented in figure 12.

\subsection{Forced vibration analysis}

A sample horizontal response at bearing location 1 obtained in time domain at $17 \mathrm{~Hz}$ of rotor speed for different order of misalignment is shown in figure 13. With the help of Eqs. (7) and (8), one may calculate the amplitude and phase of response signals due to misalignment conditions. This information was used to obtain the complex (i.e., the real and the imaginary) response of the signal. Now by using
Eq. (6), BCDPs and RUs were evaluated for a different order of misalignment (refer table 4).

\subsection{Pure angular misalignment}

Under the pure angular misalignment, two different sets of misalignment condition, mentioned in table 4, were considered. A comparative analysis of fluctuations in evaluated parameters for aligned case with respect to the aforementioned case is shown in figure 14. From figure 14, one may analyse that as the order of flaw is raised, the fluctuation in the estimated parameters is also raised; especially the crosscoupled bearing damping parameters. In this case, there are extreme deviations for Set $X_{1}$ was $c_{y x}^{B_{4}}(12 \%)$ and for Set $X_{2}$ $c_{y x}^{B_{4}}(18 \%)$.

\subsection{Pure parallel misalignment}

Next, experiments were carried out for conditions as mentioned in table 4. Figure 15 represents the comparison of errors of evaluated parameters under two different sets of parallel misalignment conditions. From figure 15, one may observe that as the order of flaw is raised, fluctuation in the estimated BCDPs also increases. The maximum deviation that took place for Set $Y_{1}$ was $c_{y x}^{B_{4}}(31 \%)$ and for Set $Y_{2}$ was $c_{y x}^{B_{4}}(56 \%)$. On comparing figures 14 and 15, one may 

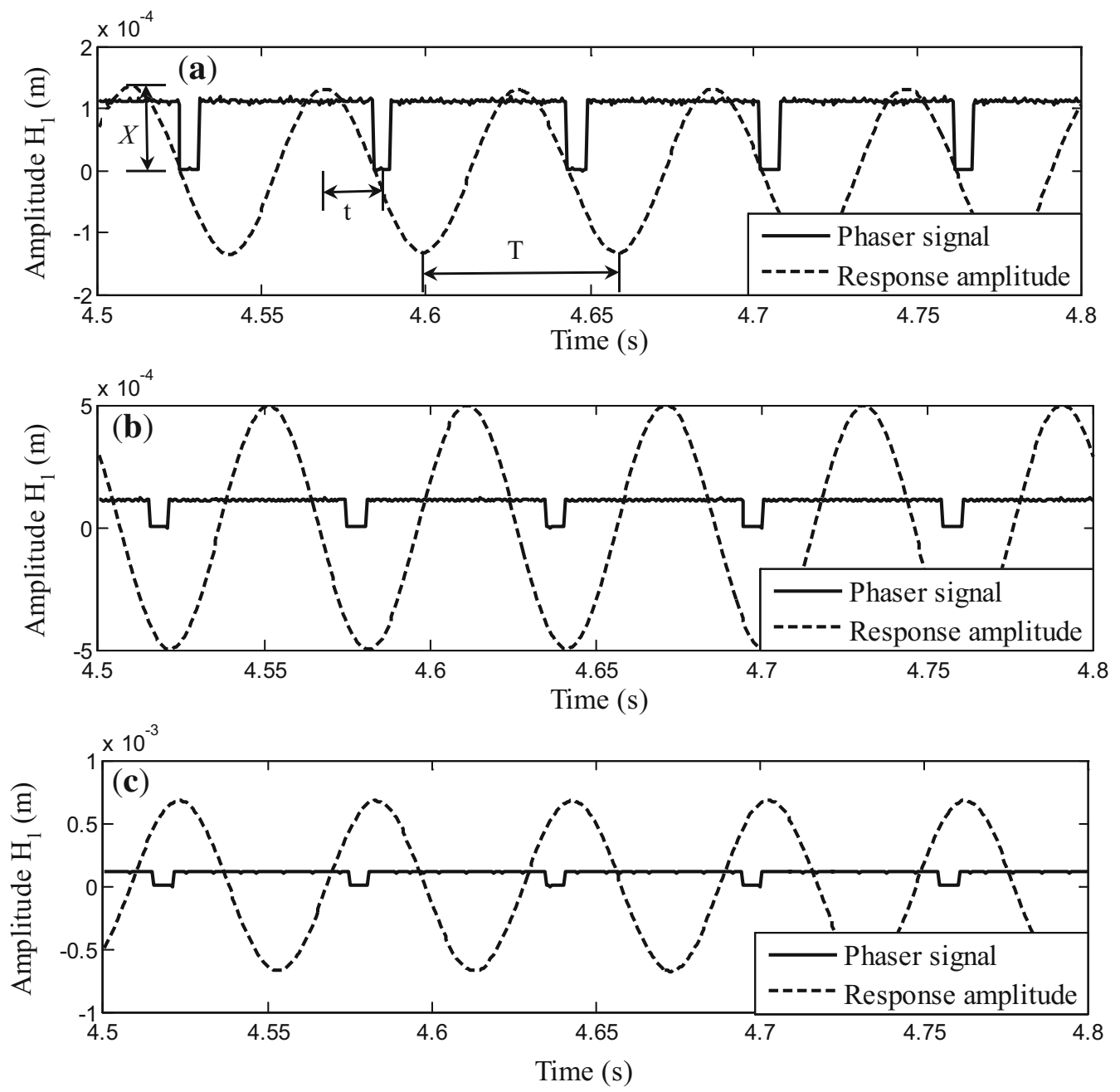

Figure 13. Horizontal response at bearing 1 for (a) Set $X_{1}$, (b) Set $Y_{l}$ and (c) Set $Z_{l}$ generated at $17 \mathrm{~Hz}$ as well as phase signal.

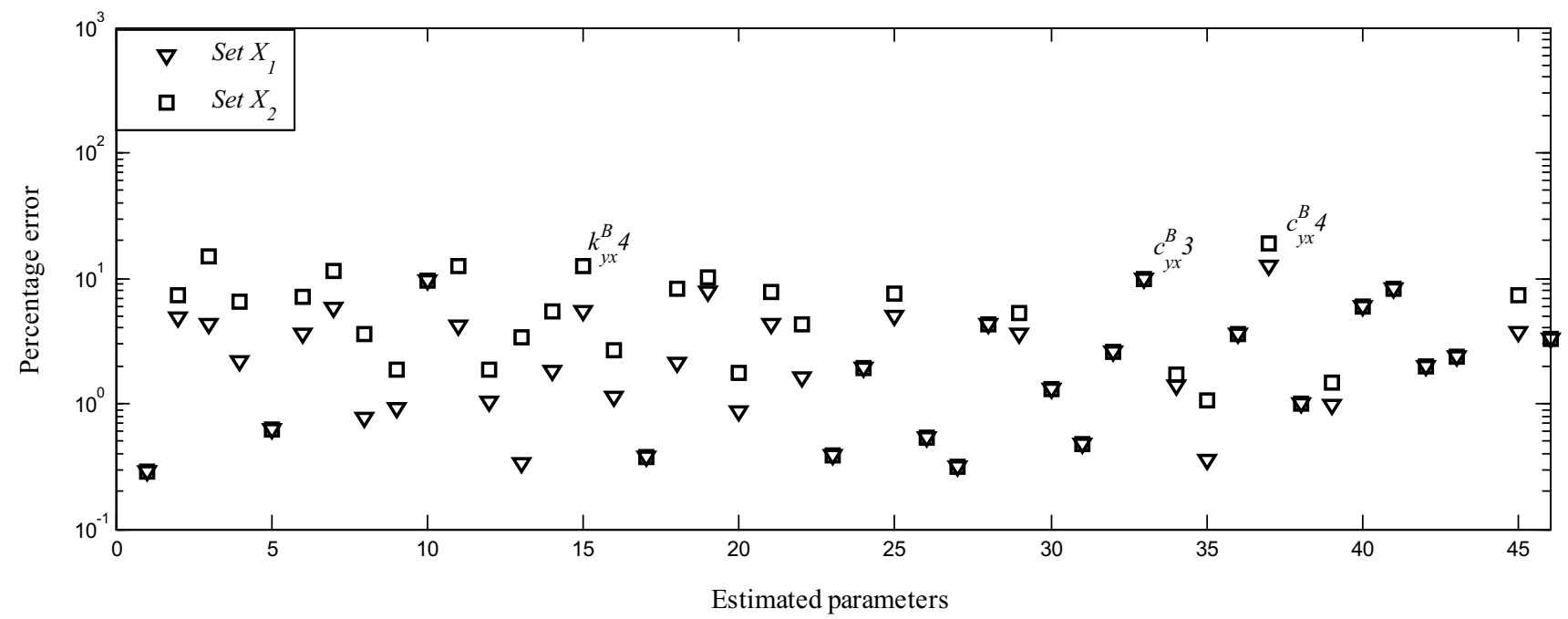

Figure 14. Estimation error in identified parameters for $\operatorname{Set} X_{1}\left(\Delta \Phi=0.16^{\circ}, \Delta \varepsilon=0 \mathrm{~mm}\right)$ and $\operatorname{Set} X_{2}\left(\Delta \Phi=0.32^{\circ}, \Delta \varepsilon=0 \mathrm{~mm}\right)$. 


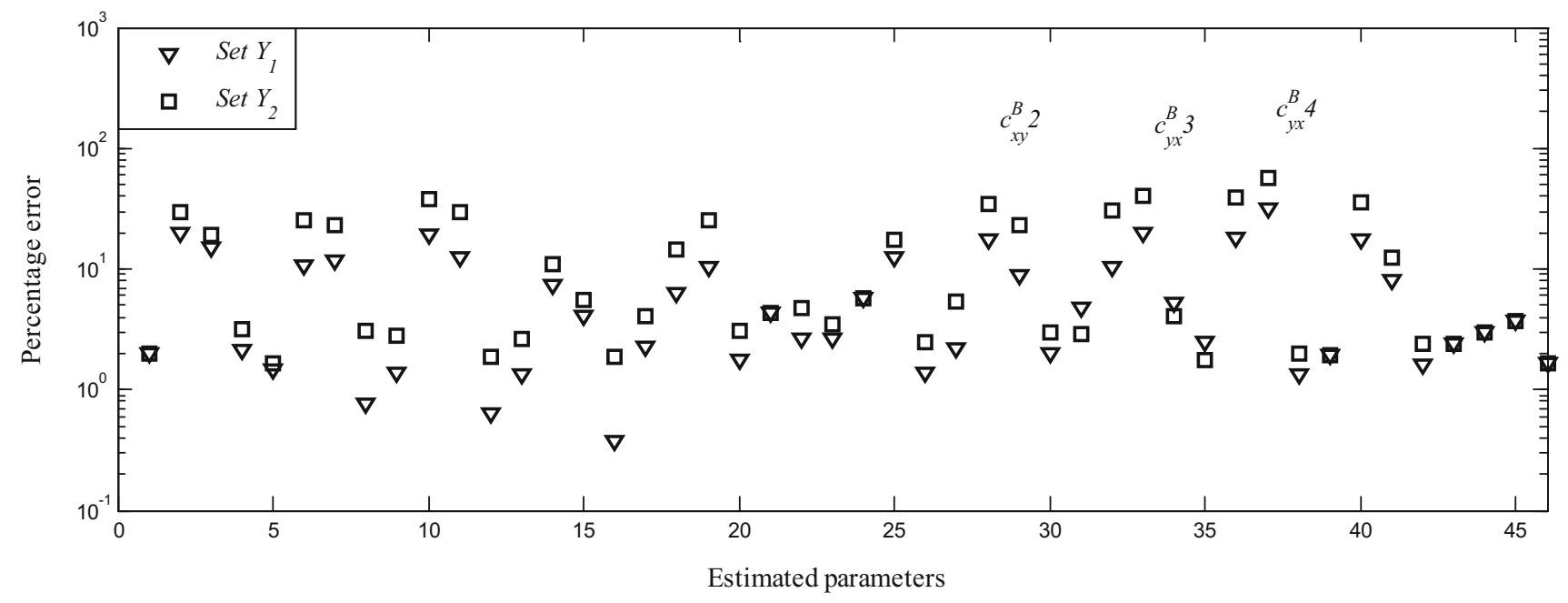

Figure 15. Estimation error in identified parameters for Set $Y_{I}\left(\Delta \Phi=0^{\circ}, \Delta \varepsilon=0.5 \mathrm{~mm}\right)$ and $\operatorname{Set} Y_{2}\left(\Delta \Phi=0^{\circ}, \Delta \varepsilon=1.0 \mathrm{~mm}\right)$.

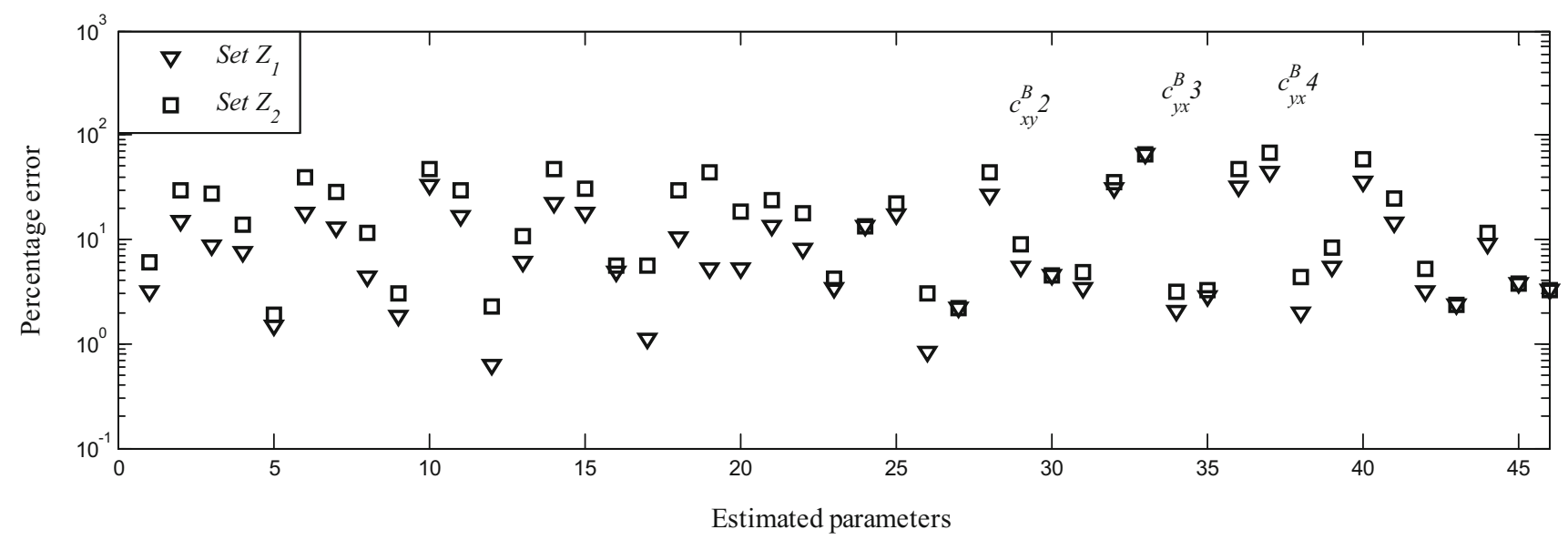

Figure 16. Estimation error in identified parameters for $\operatorname{Set} Z_{l}\left(\Delta \Phi=0.16^{\circ}, \Delta \varepsilon=0.5 \mathrm{~mm}\right)$ and $\operatorname{Set} Z_{2}\left(\Delta \Phi=0.32^{\circ}, \Delta \varepsilon=1.0 \mathrm{~mm}\right)$.

analyse that the deviation in the estimated parameters is comparatively more for the aforementioned case as compared to previous cases, i.e. Sets $X_{1}$ and $X_{2}$.

\subsection{Combined misalignment}

Thereafter, the experiment is carried out for most common misalignment condition, i.e. combined misalignment. Different sets and order of misalignment for a combined case is mentioned in table 4. A comparative analysis of deviations in evaluated parameters under combined misalignment conditions is shown in figure 16. Figure 16 shows that as the order of fault is raised, few evaluated bearing parameters, mainly cross-coupled damping, is also raised. The extreme deviation observed for Set $Z_{1}$ is $c_{y x}^{B_{4}}(60 \%)$ and for Set $Z_{2}$ is $c_{y x}^{B_{4}}(68 \%)$. From figures 14, 15 and 16, one may conclude that the deviation in evaluated parameters is highest for combined misalignment case, as compared to pure angular and pure parallel misalignment conditions.

After estimating the BCDPs and RUs with misalignment conditions, the next step is the validation of these parameters and discussed in the subsequent section.

\section{Validation of evaluated dynamic parameters with misalignment conditions}

\subsection{Free vibration analysis}

The standard impact test was performed on the misaligned rotor system for different misalignment conditions mentioned in table 4. On comparing the impact test, FFT response plots under misalignment conditions (i.e. figures 17, 18 and 19) and without misalignment conditions (i.e. figure 8), a slight variation in natural frequencies is observed (refer table 6). From table 6, it can 


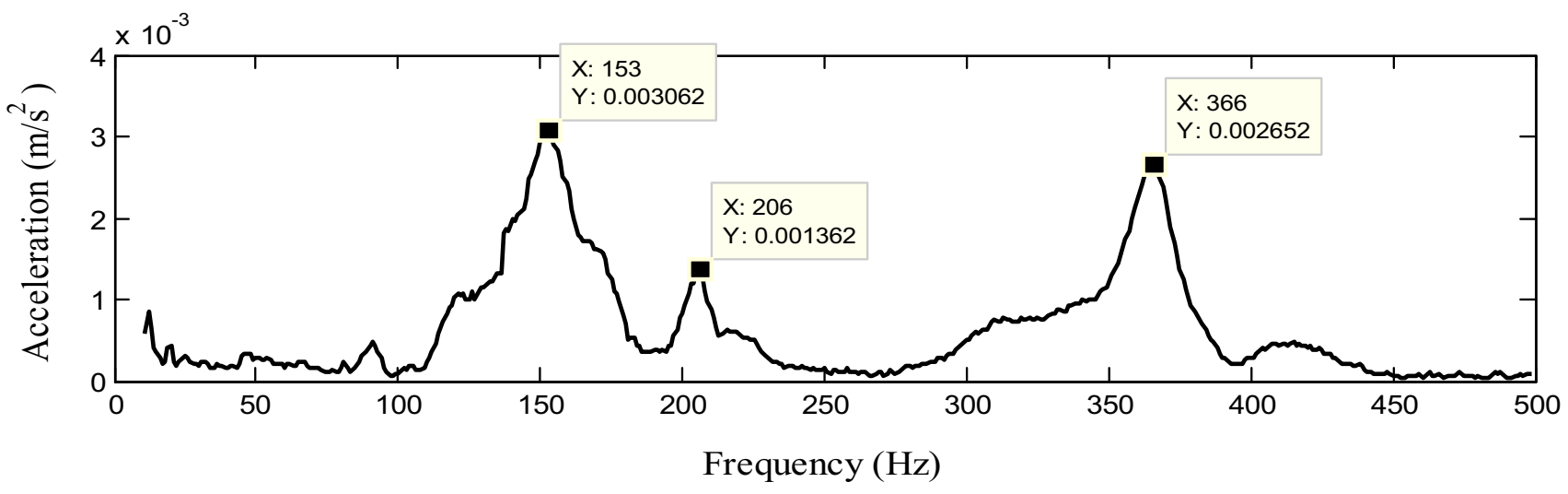

Figure 17. FFT of response for $\operatorname{Set} X_{I}$ (i.e. $\Delta \Phi=0.16^{\circ}, \Delta \varepsilon=0 \mathrm{~mm}$ ).

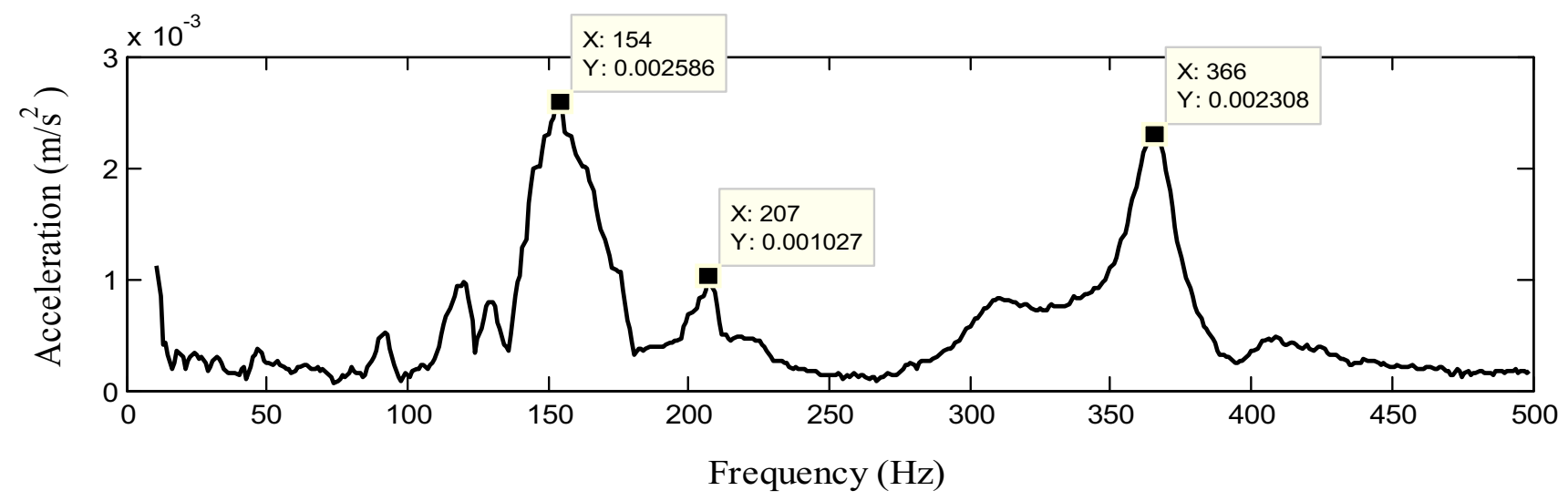

Figure 18. FFT of response for Set $Y_{1}$ (i.e. $\Delta \Phi=0^{\circ}, \Delta \varepsilon=0.5 \mathrm{~mm}$ ).

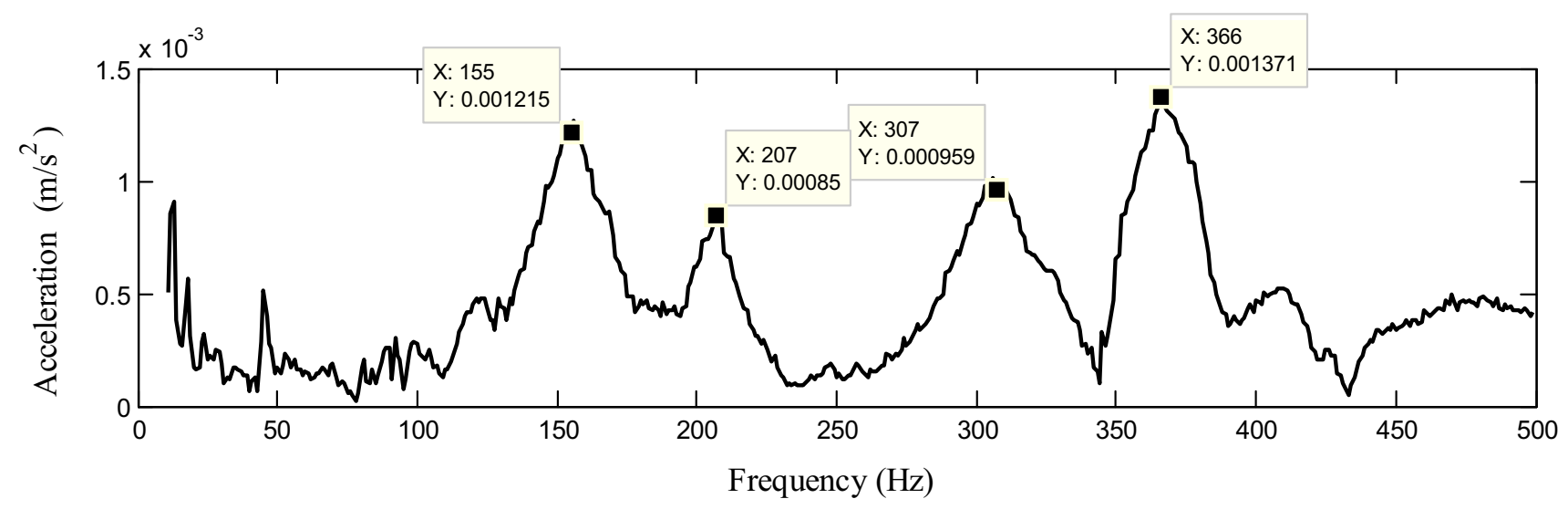

Figure 19. FFT of response for Set $Z_{l}$ (i.e. $\Delta \Phi=0.16^{\circ}, \Delta \varepsilon=0.5 \mathrm{~mm}$ ).

be analysed that misalignment causes the natural frequencies of the system to increase. This is due to the increase in effective support stiffness caused after the misalignment. On comparing figures 17-19 with figure 8, an extra peak in between the second and third natural frequencies of the previous case (i.e. the aligned case) appears at $307 \mathrm{~Hz}$. It could also be concluded that the outcome of severe misalignment is due to anisotropic 
Table 6. Comparison of natural frequencies with and without misalignment conditions.

\begin{tabular}{|c|c|c|c|c|c|}
\hline \multirow[b]{3}{*}{ S. N. } & \multirow[b]{3}{*}{ Natural frequencies $(\mathrm{Hz})$} & \multicolumn{4}{|c|}{ Impact test result } \\
\hline & & \multirow[b]{2}{*}{ Without misalignment } & \multicolumn{3}{|c|}{ With misalignment (percentage deviation) } \\
\hline & & & Pure angular $\left(\right.$ Set $\left.X_{l}\right)$ & Pure parallel $\left(\right.$ Set $\left.Y_{l}\right)$ & Combined $\left(\text { Set } Z_{I}\right)^{*}$ \\
\hline 1 & $1 \mathrm{st}$ & 150 & $153(2.0)$ & $154(2.66)$ & $156(4.00)$ \\
\hline 2 & 2nd & 203 & $206(1.40)$ & $207(1.97)$ & $207(1.97)$ \\
\hline 3 & $3 \mathrm{rd}$ & 364 & $366 *(0.54)$ & $366^{*}(0.54)$ & $366 *(0.54)$ \\
\hline
\end{tabular}

*There was an additional peak at $307 \mathrm{~Hz}$ due to splitting of third natural frequency due to anisotropy of the support condition in case of the severe misalignment.

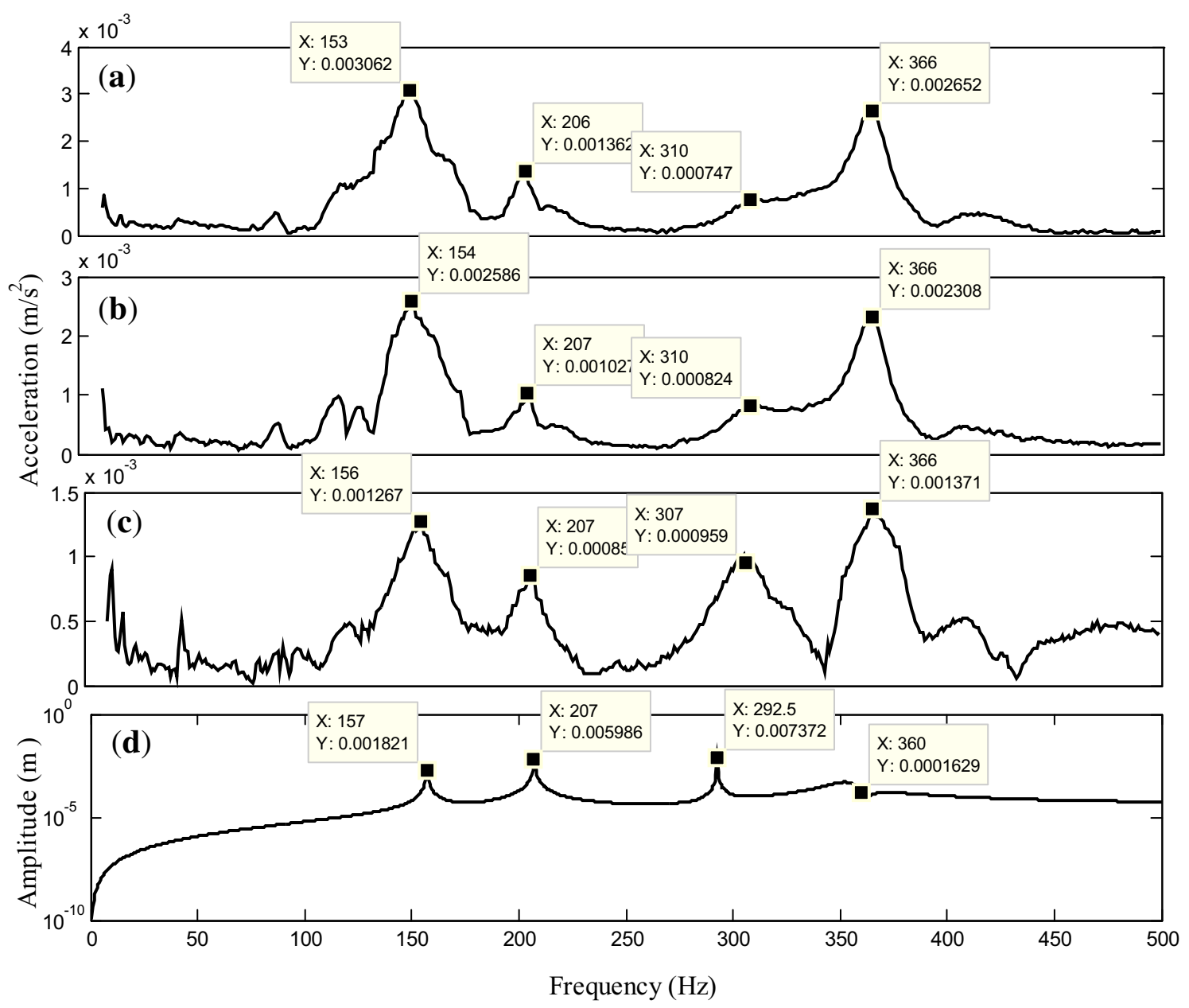

Figure 20. Comparison of natural frequencies (a) impact test for Set $X_{1}$, (b) impact test for Set $Y_{1}$, (c) impact test for Set $Z_{1}$ and (d) updated FE model with misalignment condition (critical speeds).

support flexibility that resulted in appearance of an extra peak.

After the estimation of BCDPs and RUs for various misaligned conditions, this information was used to update the FE model. The close matching could be observed between natural frequencies obtained experimentally, i.e. figure $20 \mathrm{a}-\mathrm{c}$, and the forward critical speeds obtained from the updated FE model, i.e. figure 20(d). It is interesting to note that even the splitting of natural frequencies could be simulated from the updated model, which gives further confidence on the estimated BCDPs. The effect of gyroscopic couple on estimates is negligible due to the overall symmetry in the structure. 
Table 7. Summary of natural frequencies/critical speeds with and without misalignment conditions.

\begin{tabular}{|c|c|c|c|c|c|c|c|c|c|c|}
\hline \multirow[b]{3}{*}{$\begin{array}{l}\text { S. } \\
\text { N. }\end{array}$} & \multirow{3}{*}{$\begin{array}{c}\text { Mode of } \\
\text { natural } \\
\text { frequency } \\
(\mathrm{Hz})\end{array}$} & \multirow{3}{*}{$\begin{array}{c}\text { FE modelling } \\
\text { with SSBc* } \\
\text { (critical } \\
\text { speeds) }\end{array}$} & \multicolumn{4}{|c|}{ Without misalignment } & \multicolumn{4}{|c|}{ With misalignment } \\
\hline & & & \multicolumn{3}{|c|}{ Impact test result } & \multirow{2}{*}{$\begin{array}{l}\text { Updated FE } \\
\text { model } \\
\text { (critical } \\
\text { speeds) }\end{array}$} & \multicolumn{3}{|c|}{ Impact test result } & \multirow{2}{*}{$\begin{array}{l}\text { Updated FE } \\
\text { model } \\
\text { (critical } \\
\text { speeds) }\end{array}$} \\
\hline & & & $\begin{array}{l}\text { 1st mode } \\
\text { excitation }\end{array}$ & $\begin{array}{l}\text { 2nd mode } \\
\text { excitation }\end{array}$ & $\begin{array}{l}\text { 3rd mode } \\
\text { excitation }\end{array}$ & & $\begin{array}{c}\text { Pure } \\
\text { angular } \\
\left(\text { Set } X_{l}\right)\end{array}$ & $\begin{array}{c}\text { Pure } \\
\text { parallel } \\
\left(\operatorname{Set} Y_{1}\right)\end{array}$ & $\begin{array}{l}\text { Combined } \\
\left(\text { Set } Z_{l}\right)\end{array}$ & \\
\hline 1 & $1 \mathrm{st}$ & 155 & 150 & 150 & 150 & 150 & 153 & 154 & 156 & 157 \\
\hline 2 & 2nd & 239 & 203 & 204 & 205 & 205 & 206 & 207 & 207 & 207 \\
\hline 3 & $3 \mathrm{rd}$ & 419 & 364 & 363 & 363 & 363 & 366 & 366 & 366 & 360 \\
\hline 4 & Splitting $^{\dagger}$ & - & - & - & - & - & 310 & 310 & 307 & 292.5 \\
\hline
\end{tabular}

*SSBc: Simply supported boundary conditions

$\dagger$ Additional natural frequency due to severe misalignment.

From table 6 , it should be noted that the effects on natural frequencies due to misalignments were appreciably small; however, effects on estimated BCDPs were significant. This result could be used to find the condition of misalignments. However, it has been observed that in the case of severe misalignments, additional peaks appear in the impulse response. This further confirms the misalignment at the couplings and bearings (table 7).

\section{Conclusions}

The present article focuses on an experimental investigation performed on self-developed laboratory test rig to estimate the BCDPs and RUs. Rotor shaft displacements (only linear and not the angular displacement) were measured for different cases with and without misalignment conditions to estimate BCDPs and RUs. After the estimation, the accuracy of evaluated dynamic parameters is validated by comparing the measured and predicted frequency spectra obtained from standard impact test, and it is observed that theoretical responses are in good agreement with experimental responses. Further, presence of misalignment in the system is conformed, due to the splitting of natural frequencies, even at stationary condition. The updated FE model also mimics the similar behaviours to establish the robustness and the effectiveness of the identification algorithm. Implementation of the present methodology in a real turbine-generator vibration data would be an interesting challenge.

\section{Appendix A: Timoshenko Beam Model [43]}

\section{A.1. Translational mass matrix}

$$
\left[M_{t}\right]=\left[M_{t}\right]_{0}+\phi\left[M_{t}\right]_{1}+\phi^{2}\left[M_{t}\right]_{2}
$$




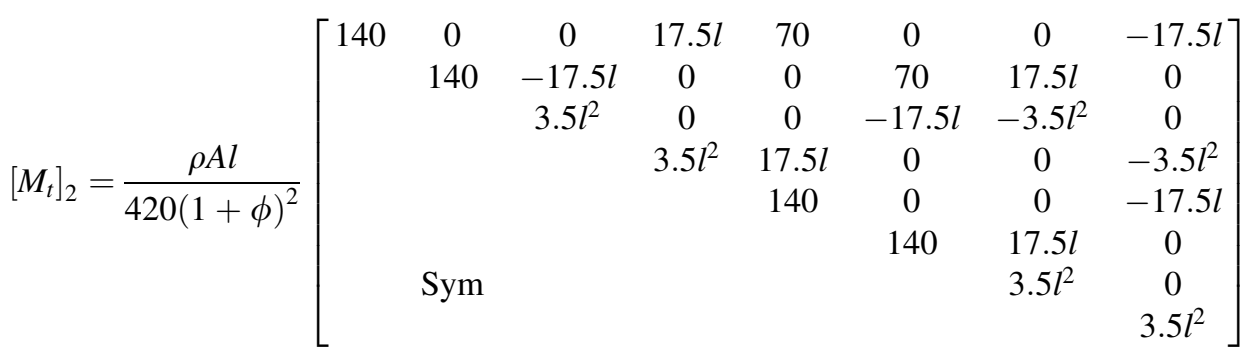

with

$$
\phi=\frac{12 E I}{k_{s c} G A l^{2}}, \quad k_{s c}=\frac{6(1+v)}{(7+6 v)}
$$

Displacement vector $\{\eta\}^{S}=\left\{x_{i}, y_{i}, \varphi_{x_{i}}, \varphi_{y_{i}}, x_{i+1}, y_{i+1}\right.$, $\left.\varphi_{x_{i+1}}, \varphi_{y_{i+1}}\right\}^{T}$, where sub-script $i$ is element number

\section{A.2. Rotational mass matrix}

$$
\left[M_{r}\right]=\left[M_{r}\right]_{0}+\phi\left[M_{r}\right]_{1}+\phi^{2}\left[M_{r}\right]_{2}
$$

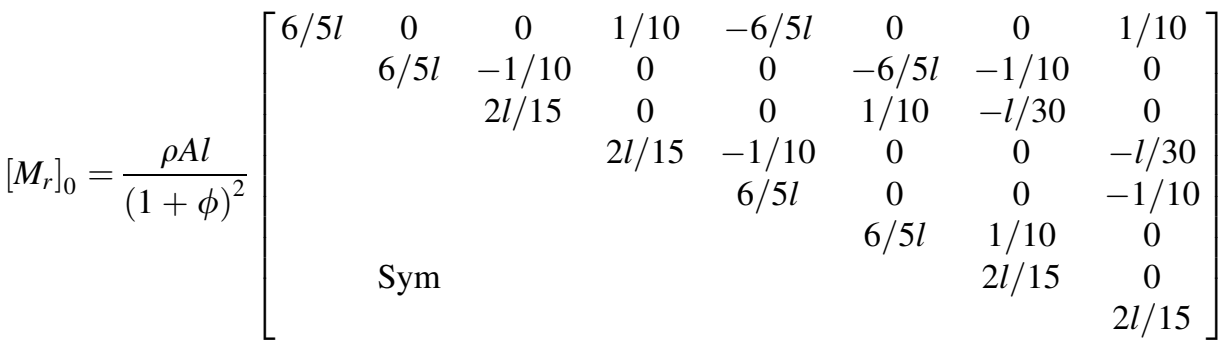

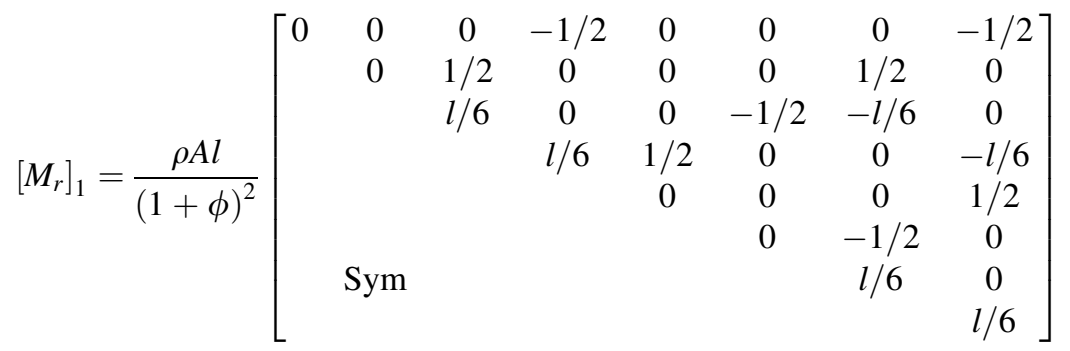

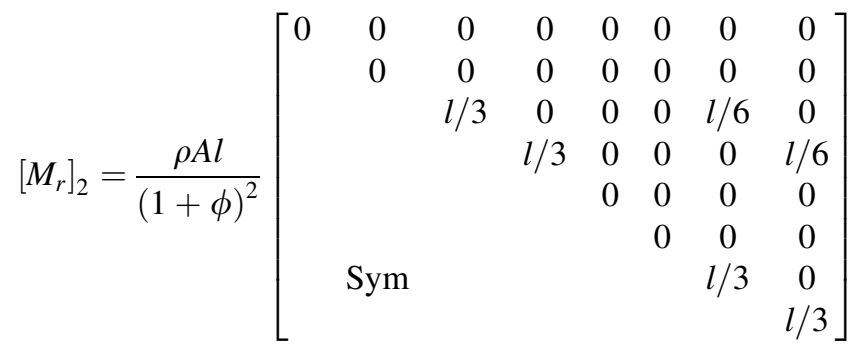




\section{A.3. Stiffness matrix}

$$
\begin{aligned}
& {[K]=[K]_{0}+\phi[K]_{1}}
\end{aligned}
$$

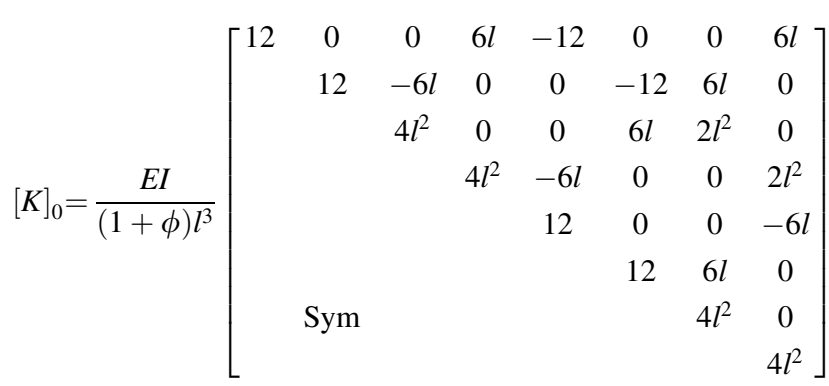

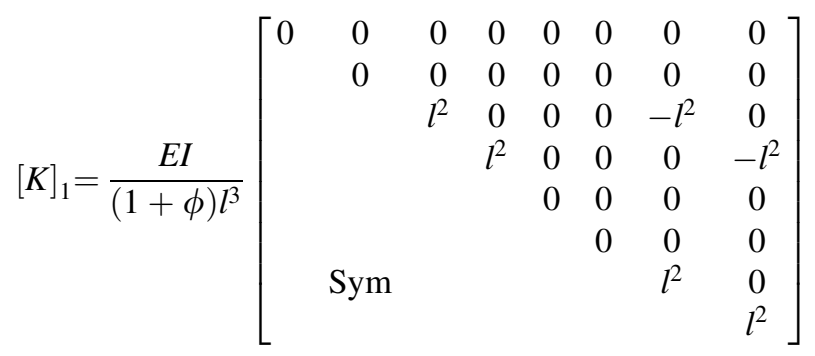

\section{A.4. Gyroscopic matrix}

$$
[G]=[G]_{0}+\phi[G]_{1}+\phi^{2}[G]_{2}
$$

$$
[G]_{0}=\frac{\rho A r^{2}}{60(1+\phi)^{2} l}\left[\begin{array}{cccccccc}
0 & 36 & -3 l & 0 & 0 & -36 & -3 l & 0 \\
& 0 & 0 & -3 l & 36 & 0 & 0 & -3 l \\
& & 0 & 4 l^{2} & -3 l & 0 & 0 & -l^{2} \\
& & & 0 & 0 & -3 l & l^{2} & 0 \\
& & & & 0 & 36 & 3 l & 0 \\
& & & & & 0 & 0 & 3 l \\
& \text { Skew } & \text { Sym } & & & & 0 & 4 l^{2} \\
& & & & & & & 0
\end{array}\right]
$$

$$
[G]_{1}=\frac{\rho A r^{2}}{60(1+\phi)^{2} l}\left[\begin{array}{cccccccc}
0 & 0 & 15 l & 0 & 0 & 0 & 15 l & 0 \\
& 0 & 0 & 15 l & 0 & 0 & 0 & 15 l \\
& & 0 & 5 l^{2} & 15 l & 0 & 0 & -5 l^{2} \\
& & & 0 & 0 & 15 l & 5 l^{2} & 0 \\
& & & & 0 & 0 & 0 & -15 l \\
& & & & & 0 & 0 & 5 l^{2} \\
& \text { Skew } & \text { Sym } & & & & 0 & 5 l^{2} \\
& & & & & & & 0
\end{array}\right]
$$

$$
[G]_{2}=\frac{\rho A r^{2}}{60(1+\phi)^{2} l}\left[\begin{array}{cccccccc}
0 & 0 & 0 & 0 & 0 & 0 & 0 & 0 \\
& 0 & 0 & 0 & 0 & 0 & 0 & 0 \\
& & 10 l^{2} & 0 & 0 & 0 & 0 & 5 l^{2} \\
& & & 0 & 0 & 0 & 5 l^{2} & 0 \\
& & & & 0 & 0 & 0 & 0 \\
& & & & & 0 & 0 & 0 \\
& \text { Skew } & \text { Sym } & & & & 0 & 10 l^{2} \\
& & & & & & & 0
\end{array}\right]
$$

\section{A.5. Rigid disc model}

Mass matrix

$$
[M]^{d}=\left[\begin{array}{cccc}
m_{d} & 0 & 0 & 0 \\
0 & m_{d} & 0 & 0 \\
0 & 0 & I_{d} & 0 \\
0 & 0 & 0 & I_{d}
\end{array}\right]
$$

Gyroscopic matrix

$$
[G]^{d}=\left[\begin{array}{cccc}
0 & 0 & 0 & 0 \\
0 & 0 & 0 & 0 \\
0 & 0 & 0 & I_{p} \\
0 & 0 & -I_{p} & 0
\end{array}\right]
$$

Displacement vector

$$
\{\eta\}^{d}=\left\{x, y, \varphi_{x}, \varphi_{y}\right\}^{T}
$$

\section{Appendix B: Natural Frequencies for Simply Supported Rotor Systems}

Closed form solution is provided to obtain natural frequency of a simply supported rotor system with massless shaft and a disc at mid-span is given as

$$
\omega_{n f}=\frac{1}{2 \pi} \sqrt{\frac{k}{m}} \mathrm{~Hz}
$$

where

$$
k=\frac{48 E I}{L^{3}}
$$

Material properties and rotor dimensions are taken from table 1 and natural frequencies are summarised in table B1.

Table B1. Natural frequencies with simply supported boundary conditions.

\begin{tabular}{lcc}
\hline S. N. & System & Natural frequencies $(\mathrm{Hz})$ \\
\hline 1 & Rotor 1 & 373 \\
2 & Rotor 2 & 169 \\
\hline
\end{tabular}




\section{References}

[1] Gnielka P 1983 Modal balancing of flexible rotors without test runs: an experimental investigation. J. Sound Vibr. 90: 157-172

[2] Morton P G 1985 Modal balancing of flexible shafts without trial weights. Proc. IMechE. Part C. Mechanical Engineering Science 199(1): 71-78

[3] Edwards S, Lees A W and Friswell M I 1998 Fault diagnosis of rotating machinery. Shock Vib. Dig. 30: 4-13

[4] Zhou S and Shi J 2001 Active balancing and vibration control of rotating machinery: A survey. Shock Vib. Dig. 33(4) 361-371

[5] Tiwari R 2005 Conditioning of regression matrices for simultaneous estimation of the residual unbalance and bearing dynamics parameters. Mech. Syst. Signal. Process. 19: 1085-1095

[6] Jardine A K S, Lin D and Banjevic D 2006 A review on machinery diagnostics and prognostics implementing condition-based maintenance. Mech. Syst. Signal. Process. 20: 1483-1510

[7] Lees A W, Sinha J K and Friswell M I 2009 Model-based identification of rotating machines. Mech. Syst. Signal. Process. Special Issue: Inverse Problems. 23: 1884-1893

[8] Edwards S, Lees A W and Friswell M I 2000 Experimental identification of excitation and support parameters of a flexible rotor bearing foundation system from a single run down. J. Sound Vibr. 232: 963-992

[9] Jain J R and Kundra T K 2004 Model based online diagnosis of unbalance and transverse fatigue crack in rotor systems. Mech. Res. Commun. 31: 557-568

[10] Sudhakar G N D S and Sekhar A S 2011 Identification of unbalance in a rotor bearing system. J. Sound Vibr. 330 (10): 229-2313

[11] Zhang Z X, Zhang Q, Li X L and Qian T L 2011 The wholebeat correlation method for the identification of an unbalance response of a dual-rotor system with a slight rotating speed difference. Mech. Syst. Signal. Process. 25: 1667-1673

[12] Lees A W and Friswell M I 1997 The evaluation of rotor unbalance in flexibly mounted machines. J. Sound Vibr. 208 (5): 671-683

[13] Naucler P and Soderstrom T 2010 Unbalance estimation using linear and nonlinear regression. Automatica 46: 1752-1761

[14] Gibbons C B 1976 Coupling misalignment forces, $5^{\text {th }}$ Turbo Machinery Symposium. Gas Turbine Laboratories. Texas A \& M University College Station Texas. 111-116

[15] Xu M and Marangoni R 1994a Vibration analysis of a motor flexible coupling rotor system subjected to misalignment and unbalance - Part 1: Theoretical model and analysis. J. Sound Vibr. 176: 663-679

[16] Xu M and Marangoni R 1994b Vibration analysis of a motor flexible coupling rotor system subjected to misalignment and unbalance - Part 2: Experimental validation. J. Sound Vibr. 176: 681-691

[17] Sekhar A S and Prabhu B S 1995 Effect of coupling misalignment on vibration of rotating machines. J. Sound Vibr. 185: 655-671

[18] Lee Y S and Lee C W 1999 Modelling and vibration analysis of misaligned rotor ball bearing systems. J. Sound Vibr. 224: 1-12
[19] Li M and Yu L 2001 Analysis of the coupled lateral torsional vibration of a rotor bearing system with a misaligned gear coupling. J. Sound Vibr. 243: 283-300

[20] Al-Hussain K M and Redmond I 2002 Dynamic response of two rotors connected by rigid mechanical coupling with parallel misalignment. J. Sound Vibr. 249: 483-498

[21] Prabhakar S, Sekhar A S and Mohanty A R 2002 Crack versus coupling misalignment in a transient rotor system. $J$. Sound Vibr. 256: 773-786

[22] Sinha J K, Lees A W and Frishwell M I 2004 Estimating unbalance and misalignment of a flexible rotating machine from a single run down. J. Sound Vibr. 272: 967-989

[23] Pennacchi P and Vania A 2005 Diagnosis and model based identification of a coupling misalignment. Shock Vibr. 12: 293-308

[24] Lees A W 2007 Misalignment in rigidly coupled rotor. $J$. Sound Vibr. 305: 261-271

[25] Patel T H and Darpe A K 2009 Vibration response of misaligned rotors. J. Sound Vibr. 325: 609-628

[26] Jalan A K and Mohanty A R 2009 Model based fault diagnosis of a rotor bearing system for misalignment and unbalance under steady state condition. J. Sound Vibr. 327: 604-622

[27] Sarkar S, Nandi A, Neogy S, Dutt J K and Kundra T K 2010 Finite element analysis of misaligned rotors on oil-film bearings. Sadhana Ind. Acad. Sci. 35: 45-61

[28] Ganesan S and Padmanabhan C 2011 Modelling of parametric excitation of a flexible coupling-rotor system due to misalignment. In: Proc. IMechE Part-C: J. Mech. Eng. Sci. 225: 2907-2918

[29] Tadeo A T, Cavalca K L and Brennan M J 2011 Dynamic characterization of a mechanical coupling for a rotating shaft. In: Proc. IMechE Part-C: J. Mech. Eng. Sci. 225: 604-616

[30] Tiwari R, Lees A W and Friswell M I 2004 Identification of dynamic bearing parameters: A review. Shock. Vib. Dig. 36: 99-124

[31] Tiwari R, Manikandan S and Dwivedy S K 2005 A review on experimental estimation of the rotor dynamic parameters of seals. Shock. Vib. Dig. 37: 261-284

[32] Sinha J K, Frishwell M I and Lees A W 2002 The identification of the unbalance and the foundation model of a flexible rotating machine from a single run down. Mech. Syst. Signal. Process. 16 (2): 255-271

[33] Bachschmid N, Pennacchi P and Vania A 2002 Identification of multiple faults in rotor systems. J. Sound Vibr. 254: 327-366

[34] Pennacchi P, Bachschmid N, Vania A, Zanetta G A and Gregori L 2006 Use of modal representation for the supporting structure in model based fault identification of large rotating machinery: Part 1 theoretical remarks. Mech. Syst. Signal. Process. 20: 662-681

[35] Ping J J and Guang M A 2009 Novel method for multi fault diagnosis of rotor system. Mech. Mach. Theory 44: 697-709

[36] Singh S K and Tiwari R 2010 Identification of a multi crack in a shaft system using transverse frequency response functions. Mech. Mach. Theory. 45: 1813-1827

[37] Yang Q W 2011 A new damage identification method based on structural flexibility disassembly. J. Vibr. Control 17 (7): 1000-1008 
[38] Lal M and Tiwari R 2012 Multi-fault identification in simple rotor-bearing-coupling systems based on forced response measurements. Mech. Mach. Theory. 51: 87-109

[39] Lal M and Tiwari R 2012 Identification of multiple faults with incomplete response measurements in rotorbearing-coupling systems. In: ASME Gas Turbine India Conference. December 1. Mumbai India (GT India 2012-9542)

[40] Lal M and Tiwari R 2014 Experimental estimation of misalignment effects in rotor-bearing-coupling systems. In: Proceedings of IFToMM 9th International Conference on
Rotordynamics. September 22-25. Politecnico di Milano Milan Italy

[41] Lal M and Tiwari R 2013 Quantification of multiple fault parameters in flexible turbo-generator systems with incomplete rundown vibration data. Mech. Syst. Signal Process. 41(1): 546-563

[42] Tiwari R 2017 Rotor Systems: Analysis and Identification. Boca Raton: CRC Press, Taylor and Francis Group

[43] Zorzi E S and Nelson H D 1977 Finite element simulation of rotor-bearing systems with internal damping. ASME: J Eng. Power 99 (1): 71-76 